This is a self-archived - parallel published version of this article in the publication archive of the University of Vaasa. It might differ from the original.

\title{
Cloud manufacturing ecosystem analysis and design
}

Author(s): Helo, Petri; Hao, Yuqiuge; Toshev, Rayko; Boldosova, Valeriia

Title: $\quad$ Cloud manufacturing ecosystem analysis and design

Year: $\quad 2021$

Version: Accepted manuscript

Copyright (C)2021 Elsevier. This manuscript version is made available under the Creative Commons Attribution-NonCommercial-NoDerivatives 4.0 International (CC BY-NC-ND 4.0) license, https://creativecommons.org/licenses/by-nc-nd/4.o/

Please cite the original version:

Helo, P., Hao, Y., Toshev, R. \& Boldosova, V. (2021). Cloud manufacturing ecosystem analysis and design. Robotics and ComputerIntegrated Manufacturing 67, 1-15. https://doi.org/10.1016/j.rcim.2020.102050 


\title{
Cloud Manufacturing Ecosystem Analysis and Design
}

\author{
Petri Helo \\ University of Vaasa \\ Networked Value Systems \\ PO Box 700, FI-65280 Vaasa, Finland \\ phelo@uva.fi \\ Yuqiuge Hao (corresponding author) \\ University of Vaasa \\ Networked Value Systems \\ PO Box 700, FI-65280 Vaasa, Finland \\ yuqiuge.hao@uva.fi \\ Valeriia Boldosova \\ University of Vaasa \\ Networked Value Systems \\ PO Box 700, FI-65280 Vaasa, Finland \\ valeriia.boldosova@uva.fi \\ Rayko Toshev \\ University of Vaasa \\ Networked Value Systems \\ PO Box 700, FI-65280 Vaasa, Finland \\ rayko.toshev@uva.fi
}

\section{Abstract}

The manufacturing industry is facing the impact of a dynamic marketand intensive competition. Many companies are looking for a new approach to improve their business activities in a collaborative business ecosystem with other stakeholders. Cloud computing enables the sharing of manufacturing resources and capabilities between different stakeholders to support business and physical production. The purpose of this research is to explore approaches moving towards a cloud manufacturing ecosystem and present possible implications for practice. To fulfil the research objectives, a multiple-case study was conducted within sheet metal manufacturing companies. Business and technology related requirements for cloud-based collaborative manufacturing portals were collected through interviews with industrial practitioners from the sheet metal manufacturing perspective. Based on analysis a prototype model of a CloudEcosystem was presented to demonstrate the essential features of the portals. This research found that there are three different portal types for cloud manufacturing ecosystems depending on the value chain configuration. Close to real-time information provided by cloud-ba sed platforms can createmanufacturing ecosystems where machine owners, product designers and customers may collaborate and compete simultaneously. The 
CloudEcosystem designed in this research can provide a practical tool and technical solution to help manufacturess think about moving towards cloud manufacturing ecosystems.

\section{Keywords}

Ecosystems, web portal, cloud platform, business collaboration, cloud manufacturing.

\section{Introduction}

The business ecosystem, originating from the metaphor of the naturalecosystem, offers a niche for various business participants to collaborate, be connected in a sophisticated relationship, and be able to compete in a dynamic business environment $[1,2]$. In the manufacturing industry, companies are facing influences from varied customers' requirements, dynamic business competition - small lot sizes and short product life-cycles, and multiple advanced technologies.

New digital infrastructure and platforms a re catalysts for the fourth industrial revolution in the manufacturing industry, namely Industry 4.0 [3]. Advances in cloud computing, the Internet of Things (IoTs), blockchains [4, 5, 6], additive manufacturing $[7,8,9]$ and other emerging technologies improve productivity, produce betteroperating performance,

and increase profits. The integration of new technologies has helped to create new ecosystems for manufacturing. These manufacturing ecosystems have more autonomic and smart features in connection, collaboration and competition $[10,11]$. Cloud manufacturing is a paradigm that provides an operating framework to enable effective decentralized service control and management. It transforms manufacturing resources (both hardware and software) and capabilities (i.e., the performance of production and manufacturing) into the cloud as manufacturing services among different stakeholders $[12,13,14,15]$.

Although manufacturing ecosystems $[4,16,17]$ and cloud manufacturing have been proposed in previous studies $[5$, $18,19]$, it is still challenging for manufacturers to understand the practical approaches of adopting advanced technologies and collaborating with other participants in the manufacturing ecosystem. Manufacturers need to have knowledge of how and when to collabora te a cross organizational and geographic boundaries, and then maximize their 
business value [20]. Besides all these business requirements, it is also vital to integrate fragmented business intelligence by using an all-in-one solution.

From an academic point of view, a comprehensive analysis of processes and frameworks that would enable collaborative solutions across the manufacturing ecosystem by adopting cloud-based technologies is still lacking. Therefore, in order to deal with this research gap, the authors intend to develop a theory of cloud manufacturing ecosystems and identify the best practices for managing relationships and information within the ecosystem. By comparing with different recent developments and analysing the theoretical background, this research addresses the research question: 'how do manufacturers collaborate in a business ecosystem by using different cloud-based portals?' This paperfocuses on providing a framework for a cloud manufacturing ecosystem to support collaboration among different participants and suggests the implementation of different portal types in order to realise the cloud manufacturing ecosystem.

To address the challenges of a dynamic market in the manufacturing industry, companies share their resources and assets within the ecosystem and levera ge their capabilities with others. Thus, ecosystems enable companies to achieve leveraged business growth and business expansion together. This cloud manufacturing ecosystem is promising in terms of achieving a business flexible and geographic distributed network to support the dynamic behaviour of manufacturing industry, establishing effective collaboration to manage the stakeholders, and enabling a move creative way to manage interactions among all stakeholders. This cloud manufacturing can make sure that different partners can create value and perform physical production together even their business objectives, orientations, and locations are differently.

This research contributes to manufacturing industry in the following aspects. First, it presents a cloud manufacturing ecosystem based on the connection between customers, manufacturers, brokers, designers and IT solution providers within the manufacturing environment. This new approach is more flexible in supporting collaboration than the tra ditionalbusiness a pproach because different parties bring an increa singly diverse set of ca pabilities to the ecosystem and community. Second, it provides a framework for describing different portal types for cloud manufacturing ecosystems. It includes different scenarios and uses cases of collaboration. Third, it proposes a prototype of cloud 
manufacturing ecosystem design, namely CloudEcosystem. Fourth, in order to verify the proposed implementation, a pilot is designed to demonstrate some features of the prototype. This prototype was implemented with three case companies, one machine builder, and two machine operating companies. In addition, individual product designers were included as well. This pilot covered examples: (1) steel parts for decorative items, architecturalpa nels, (2) custom made steelparts for roofs. Implementation of CloudEcosystem can achieve better control over business activities with both customers and other partners, enhancing collaboration and customer experience. This research is of interest not only to manufacturing companies that are interested in the best practice of cloud manufacturing ecosystems, but a lso to technology providers that deliver the foundation for collaboration in manufacturingecosystems.

This paper is an extension of work initially presented in the International Conference on Industrial Engineering and Operations Management 2017, entitled 'Cloud-based manufacturing ecosystem-application development' [21]. The paper is organized as follows: Section 2 provides a review of pervious related studies. Section 3 presents the research method and proposes the concept of cloud manufacturing ecosystem. Section 4 describes a prototype and also an example of the implementation involved in a manufacturing company. The architecture, technical implementation, and data management mechanism are also presented in this section. Finally, in Section 5 the implications of the study are presented, and in Section 6 the conclusion and possible further research are summarized.

\section{Theoretical background}

Recently, collaborative business models have come in a variety of forms in the manufacturing industry. Many companies have integrated advanced technologies with their business and production for a stronger manufacturing organization and also for a broader manufacturing ecosystem. Cloud computing and cloud-based services are the enablers for developing physical production towards on-line real-time systems within the manufacturingecosystem. Therefore, a review of recent developments in these research areas is presented in this section.

\subsection{Business ecosystem theory}

Because economics and biology have many common features, Rothschild [22] introduced the concept of bionomics and described the economy a s a business ecosystem with transactions between agents. By drawing an analogy between biological ecosystems and business ecosystems, the performance of each company is dependent on the performance 
of the whole system [1]. The business ecosystem is a metaphor that highlights the interdependence of all companies in the business environment [23]. In the natural ecosystem, each species has its significant role and impact on the evolution of other species. In this way, they construct a closely interdependent community. The concept of business ecosystems have emerged in ICT industry, where marketplaces such as Apple AppStore, Google Play or Azure Marketplace offer a distribution channel and currency transfer mechanism for thousands of software developers to offer their solution to end-users [70].

In order to create favourable and innovative business environmental conditions, companies need to develop ecosystems or clusters with each other [24]. In the business ecosystem, an individual company cannot develop fully without the same achievement level as others. The companies have different structural properties or attributes, but they share a common goal and business purpose in dealing with uncertain business environments $[1,25]$. This relationship among companies could extend the breadth of the individual company, and also create a more comprehensive view of cross-industry collaboration among different companies [26].

There are two main structures of business ecosystems. The first is the 'keystone' model, which is dominated by a large company (or several la rge companies) that is surrounded by smallsuppliers. The second model is composed of mainly SMEs (small and medium sized enterprises) that complement one another and collaborate in a more dynamic structure $[23,27]$. These two types of ecosystems are supported by internal platforms and external industry platforms, respectively [2]. Platform development is a crucial way to manage different stakeholders and deal with turbulent markets in the business ecosystem [1]. This dynamic element of turbulence can refer to changes in demand, product mix and product life-cycles as well as in the competition. It is a significant enabler of the business ecosystem. The platform is designed to leverage the available information within the entire ecosystem. Moreover, the platform can facilitate efficient interactions and distribution of responsibilities among participants [28]. Implementation of the platforms can help companies to learn about the surrounding ecosystem, and also to understand their position within this ecosystem [29].

Digitalization with advanced IT tools and a technology-enabled platform has brought a new aspect to business ecosystems in support of intensive collaboration $[3,30]$. This aspect can be referred to as digital business ecosystems 
that a im to provide companies with an open and reliable platform to interact with each other [27, 31]. When business ecosystems and digitalization co-evolve in the concept of digital business ecosystems, they eliminate boundaries between companies, between humans and machines, between producers and consumers, and between physical production and digital representation $[23,32]$.

In the technology industry, the cases of Apple's AppStore and Google's Play stores are famous examples of combining the development forces from developers and the market with mobile phone users. For instance, Apple's AppStore is a well-known and often mentioned reference to a business ecosystem where a sizeable central operator offers smaller agents (i.e., software developers) access to the market, and a platform for mobile phone end-users by using a profitsharing scheme, and a process for financialtransactions. Although Apple and Google use different business strategies, they both provide trusted access and transaction mechanisms for all parties and create innovative services [33]. The Alibaba Group is a Chinese online commerce and shopping company. Alibaba enables an integrated services platform for buyers, sellers, logistics partners, wa rehouse systems, and financialorga nizations. It achieves its business mission by supporting different business activities, such as trading in the marketplace, payment, and logistics [34].

In the transportation and logistics service providers industry, autonomous vehicles or ride-share businesses have emerged to stimulate an innovative and new mobility ecosystem. This business ecosystem coalesces around city planners, technology and energy players, public transportation providers, regulators, infrastructure and construction players, insurance companies, and peer-to-peer networks. All the actors collaborate and a dapt together to improve and transform our lives [32].

The above examples reveal how the business ecosystem can provide customers with seamless experiences of products and services. However, not all business ecosystems are emerging in an organic and evolving way ba sed on the trends. Some might develop in a more planned manner. For example, Amazon acts as a 'middleman' among sellers, buyers, advertisers, and collaborators. This is a planned business ecosystem [35]. 


\subsection{Manufacturing ecosystem}

Nowadays, customers have become more and more demanding in the manufacturing industry. They are looking for better services beyond the products. Manufacturing companies offer advanced services that can increase business performance and improve customers' experience and internal operations [28]. It has become a primary challenge and even a high priority to meet rapidly rising customer expectations. However, today's manufacturers a re struggling to keep up because most companies are rigid and geographically restricted in their current production networks [36]. Therefore, many manufacturers a re looking for a new business model to compete in the new digital environment [37]. For instance, the virtual factory is an objective-oriented collaboration model among SMEs looking for a temporary business opportunity [38]. Extended enterprise means a modeland a dominant enterprise extending its boundaries to other suppliers [39]. The grid manufacturing business model provides a pool of distributed and heterogeneous manufacturing resources [40]. However, these concepts are not comprehensive in terms of information management and business structure, and they lack central-control systems [19].

A manufacturing ecosystem extends the scope of the supply chain and covers the area of industry evolution [41], and it can help manufacturers to meet customer needs, enhance flexibility, and seize competitive advantage. The terminology of manufacturing ecosystems also relates to other concepts, such as networked value chains, holonic enterprises, virtual enterprises [42], distributed manufacturing [43], non-hierarchical networks [44], smart manufacturing [45], intelligent manufacturing [46], etc. According to Accenture Strategy research, manufacturers that use a higher percentage of partnership networks a re more likely to have higher productivity, revenue, and profit margin than those that try to build and own the entire network [36]. Ba sole et al. [47] have analysed how companies operate with each other and what kind of network was the result of dynamic behaviour. In order to address the dynamic nature of collaboration, a manufacturing ecosystem has to constantly re-align the relationships among companies and their strategies and resources [48].

There are different stakeholders in the manufacturing ecosystem, such as suppliers, distributors, logistics partners, technology providers, policymakers, and even competitors [34]. They play a significant role in the entire journey of manufacturing: from innovation, design, production, and distribution, to aftersa les services [36]. All these stakeholders work together to improve efficiencies and to optimize product and service levels. Besides different stakeholders, 
different departments are a lso tightly integrated in to the manufacturing ecosystem. Hao [49] provides a collaborative model across different organization levels and information sharing levels. The manufacturing ecosystem includes all possible aspects of product development and production processes [18]. Due to fast-evolving technologies enabling information flow and communications, integrated information management can remove the barriers and costly obsta cles between different departments and ensure that all departments can work together in parallel by information sharing mechanisms within the company.

The collaborative interactions between different partners are challenging in manufacturing ecosystem s. To optimize their collaborations, it is essential to use ICT (information and communication technology) tools to support the synchronization of interactions. Rong et al. [50] ana lyse how all cross-industry stakeholders co-operate and co-evolve in the IoT business environment through the lens of the business ecosystem. Three different levels of data/product access by industrial players are identified to classify the IoT-based business ecosystem patterns, namely high-open, medium-open, and low-open IoT-based business ecosystems.

A famous example in the manufacturing industry is additive manufacturing. In the fast-evolving industry $3 \mathrm{D}$ printing industry, many companies are going beyond merely providing hardware and material solutions, and are developing a tota13D printing ecosystem [32]. This ecosystem extends the potentialof 3D printing by changing the way of thinking about how each partnercan connect and integrate with others, as illustrated in Figure 1.

As additive manufacturing gains momentum, manufacturers will be able to buy digital representations of products (standard and proprietary) through emerging digital marketplaces and augment them via value-added digital services to meet specific marketplace needs. Once designs are completed, products can be produced in -house, via a contract manufacturer, or through an ad-hoc 3D printing service. These marketplaces and services will help manufacturers dram a tically reduce costs and time a cross innovation, design, and production [36]. Figure 1 shows examples and wellknown implementations of new business models based on additive manufacturing. They illustrate a vision of how the ecosystem will take shape. For instance, Thingiverse is an online service for different users sharing their designs for 3D printing or laser cutting. 3D Hubs is a private company offering hardware for 3D printing. Shapeways is a more comprehensive provider, which includes design, manufacture, and marketplace services for 3D printing. On the other 
hand, Ponoko, Autodesk, and OnShape are examples that provide service for industrial purposes, such as a solutions for product design and small batch production, and so on.

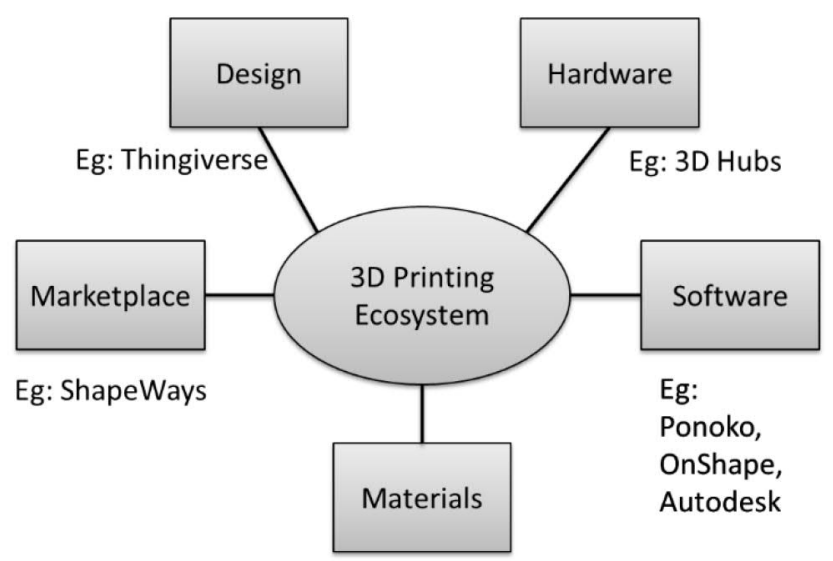

Eg: ShapeWays

Figure 1. Illustration of 3D Printing Ecosystem

Similar kinds of structures of control and management in additive manufacturing can take place in traditional manufacturing. Manufacturers need to consider how to use existing partner networks in unique ways and how to introduce new partners. Manufacturers can exchange their information with others through different approaches so that they can levera ge each other's strengths and focus on their core competences [51].

Based on current research, it has been proven that the future of manufacturing is a creative partnership network, namely networked manufacturing, such as outsourcing, and extended enterprise strategies. All the manufacturers share resources in order to achieve a business goal together because the goal is beyond the adequate scope and capabilities of any individual manufacturer. In the coming years, manufacturers across industries will undergo a steady evolution of this new manufacturing model. This phenomenon is not only applied in OEMs (original equipment manufacturers) but also to SMEs in the manufacturing industry, as mentioned in the previous section.

Most OEMs are moving towards product standardization to increase efficiency. On the other hand, SMEs are driving towards innovation and specialization. Depending on different business structures, different business objectives and different regulations, manufacturers should consider different strategies of colla boration in manufacturing ecosystems. For instance, Reynolds and Uygun [48] suggest that OEMs need to create a linkage with other SMEs from the same 
region to stimulate innovation in the manufacturing industry because they share common concerns about regional capabilities (i.e., labour force, supply chain, and infrastructure). It is also essential to establish collaboration across OEMs because they share similar suppliers. An updated supplier programme could improve the process of production and quality of the product. Razavi et a1.[27] introduce an open environment for SMEs to concentrate on their resources and capabilities, and in the meanwhile, concatenate their offered services within service chains formulated on an ecosystem.

The future of manufacturing is ecosystem -driven. Rasmus and McKinney [36] suggest more creative partnerships in manufacturing ecosystems, such as contract manufacturers for a variety of value-added services, contract logistics providers for more flexible packaging and delivery processes, and contract workers for a flexible workforce. Other practicalexamples are maintenance, repair, and operations (MRO) centres for common parts or asset management in an industry or process type.

Based on previous research and existing cases in the market, the manufacturing ecosystem can be viewed from three aspects: partners (actors in the ecosystem), businesses (values to the ecosystem), and technologies (enablers of the ecosystem), as shown in Figure 2.

- The partners include big OEMs, SME networks, ICT suppliers, universities and resea rch centres, local public authorities, individual consultants, customers and citizens working together for promoting and developing new ideas, new products, new processes, and new markets [52].

- The business in ecosystems includes all the services, manufacturing resources, manufacturing capabilities, and knowledge that support intelligent business activities throughout the entire manufacturing process.

- The technologies in ecosystems make up the ICT infrastructure design to support business activities. This ICT infrastructure ensures that an autonomous business can be interconnected by computer networks and support the formation of a coalition in order to a chieve flexibility and agility [30]. 


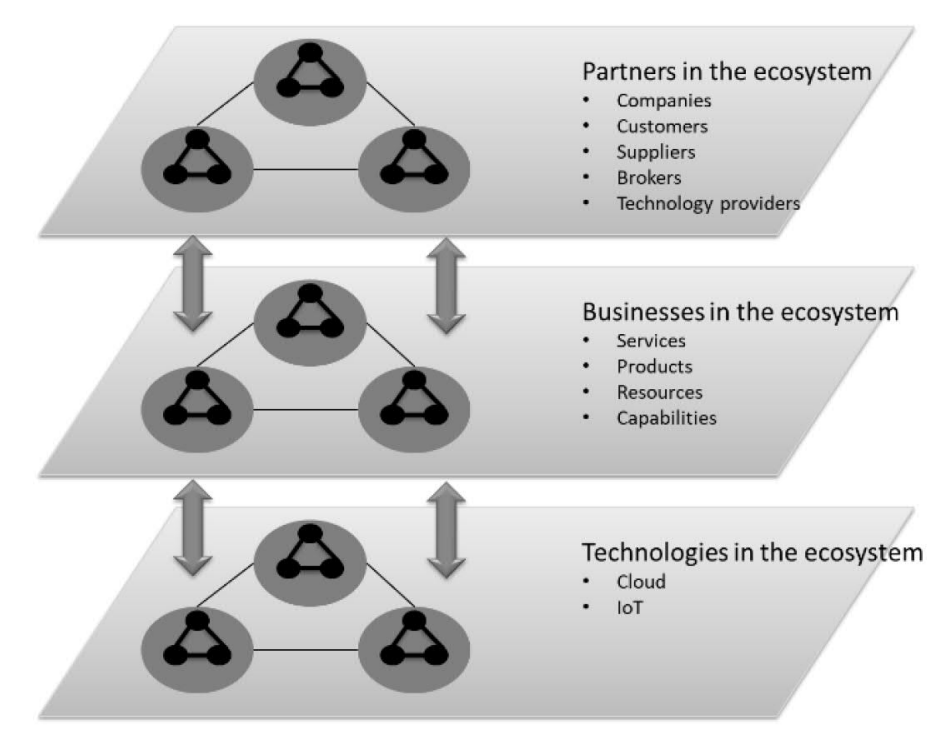

Figure 2. Stack View of the Ecosystem in Manufacturing Industry

Although the properties of a natural ecosystem contribute as fundamental elements of the business ecosystem, the business ecosystem possesses more properties than a natural one [53]. The actors are more intelligent in a business ecosystem, and they are able to plan and predict in advance. The actors aim at a high level of a chievement and success rather than pure survival. On the other hand, it is important to emphasise the importance of technologicaldevelopment in the business ecosystem. Technological convergence and innovation are the keys to driving business ecosystems [39a]. However, a high level of utilization of technologies in SMEs does not reach the high level of adjustment of integrated information systems developed for large companies.

Therefore, new technological solutions should be considered to support the relationships and collaboration between companies. Kress et a1. [29] point out that IT companies are one of the essential new players emerging in the manufacturing industry. They can offer cloud, big data, mobile computing, cyber-physical systems (CPS), a ugmented reality, RFID (radio frequency identification), machine-to-machine communication, and advanced robotics solutions for manufacturing companies to enhance automation, communication and integration within the ecosystem. For example, a manufacturing control tower is used for production monitoring a cross a network of different manufacturers, and engineering collaboration tools used for digita lized design and prototyping. 


\subsection{Cloud manufacturing}

Today, many advanced technologies, such as virtualization, service-oriented architectures (SOA), Industrial Internet of Things (IIoTs), Internet connectivity, cloud computing, big data, CPS, and other high -performance computing [20, $54,55]$ are integrated to support a paradigm shift of both IT infrastructure and business infrastructure, particularly in IT efficiency and business agility [3]. These emerging new technologies are converged as an ideal model for the delivery of collaborative solutions because of their advantages in innovation, mobility, and collaboration [18].

In the manufacturing sector, cloud manufacturing is proposed to utilize an industry-specific vertical cloud [19, 56]. The manufacturing resources, capacities, and the entire manufacturingbusiness a re realised on the cloud platform and provided as a cloud service, and shared with manufacturing stakeholders [4, 13]. However, cloud manufacturing not only focuses on providing an integrated cloud framework for converting manufacturing resources into on-demand networked manufacturing services, but a lso a ims at connecting customers with variable needs and manufacturers with specific resources/capacities to co-create personalized products and individualized services through online social platforms [57]. This creates a potential driver for distributed global manufacturing and servitization intelligent manufacturing.

Cloud manufacturing can be interpreted mainly from two aspects: using cloud-related technologies in the manufacturing industry, and cloud manufacturing applications and solutions [58]. First, the characteristics of cloud can realise the virtualization of physical objects related to manufacturing, such as machines, tools, and robots. This virtualization can enable the machines and components to be processed in virtual space, and also prepared in real space [59]. Moreover, distributed software architectures ba sed on open interfaces, such as SOA, can enable the use of distributed computing resources [12]. In the second aspect, cloud manufacturing is described as a manufacturing version of the social network that can support business sharing and integrate distributed manufacturing resources [60, 61]. It acts as a web portal and provides real-time communication and information exchange. There are three main types of stakeholders involved, namely operators, demanders, and providers [15]. Operators manage the web portal and provide searching and matching algorithms to help the demanders allocate best-fit final products or mature business services that are categorized and published in this portal by providers. Three operation modes of resource utilization are studied in previous research, namely metabolism mode, incubation mode and outsourcing mode [17]. 
However, suitable products or services are locally provided for demanders. Alibaba, ThomasNet, and Globa ISpec are good examples of this level of service system. Configuring such portal solutions through cloud-enabled development tools can reduce the idea-to-market time.

MaaS (manufacturing as a service) is an extension of cloud services from IaaS (infrastructure as a service), PaaS (platform as a service) and SaaS (software as a service). Several examples of applications can be found in previous research to demonstrate the concept of MaaS:

- Wu et al. [62] propose an online system for selling machine capacity (e.g., 3D printer);

- Luo et al. [63] show how to provide visibility for supply chain collaboration in the cloud;

- Helo and Hao [64] demonstrate production planning and scheduling as a service;

- Helo et al. [65] illustrate how a cloud-based manufacturing execution system can serve multiple factories;

- Shamsuzzoha et al. $[44,66]$ present collaborative smart manufacturing for process monitoring and product delivery.

\section{Methodology}

Although research on business ecosystems has attracted the attention of resea rchers in recent years, current literature still lacks a concrete understanding of how to achieve and implement collaborative manufacturing ecosystems by applying advanced technologies, particularly with cloud solutions. The objective of this research is to provide an empirical exploration of the new business collaboration model, namely cloud manufacturing ecosystem.

\subsection{Research approach}

Multiple sources of information are used in this research to enhance the results. In order to improve the quality of research and build a theory based on existing theory from literature review and practice from case studies, this research is carried out by the following three steps: selecting the case companies, identifying the interviewees and interview questions, and analysing data [50]. The steps conducted with the selected companies were:

(1) Requirements interview

(2) Development of CloudEcosystem software based on requirements

(3) Piloting the system in real environment 


\section{(4) Group interview after piloting}

For the first step, three case companies were involved in collecting the data. For confidential reasons, C1, C2, and C3 are used as fictional names throughout this report. They were selected for two main reasons: all three companies are small and medium-sized and involved in the manufacturing ecosystem, particularly in the sheet metal fabrication industry, and a lso they are implementing cloud-based platforms to manage their partnerships and production activities. However, each company is slightly different in terms of their motivation and purpose in adopting the cloud manufacturing ecosystem. The three case companies play different roles in the cloud manufacturing ecosystem. These case studies help to build up a comprehensive understanding of different types and activities in the cloud manufacturing ecosystem, therefore making it possible to ana lyse and design a cloud manufacturing ecosystem. Table 1 defines the selection of the case companies.

Table 1 Case selection in the research

\begin{tabular}{|c|c|c|}
\hline Company ID & Business area & Business purpose of cloud manufacturing ecosystem \\
\hline $\mathrm{C} 1$ & Machine builder & $\begin{array}{l}\text { - } \quad \text { Managing the globalized supply chain and distributed suppliers } \\
\text { - } \quad \text { Producing at different sites near customers }\end{array}$ \\
\hline $\mathrm{C} 2$ & $\begin{array}{l}\text { Machine operating } \\
\text { company }\end{array}$ & $\begin{array}{l}\text { - Outsourcing some activities that are not covered by in-house } \\
\text { competencies. } \\
\text { - Collaborating with other companies }\end{array}$ \\
\hline $\mathrm{C} 3$ & $\begin{array}{l}\text { Machine operating } \\
\text { company }\end{array}$ & $\begin{array}{l}\text { - } \quad \text { Supporting both internal and external business activities } \\
\text { - } \quad \text { Providing professional customer services by outsourcing. }\end{array}$ \\
\hline
\end{tabular}

The data collection was performed during 2017 and 2018, and three semi-structured interviews were conducted. Ten of the interviewees were manufacturing experts from the case companies, and three of them were freelance product designers. They were asked for their opinions and personal insights into the cloud manufacturing ecosystem and their business requirements of such cloud manufacturing ecosystem. This is also a requirements collecting procedure which is normally conducted in software engineering processes. Interview guidelines were prepared to increa se the reliability of the data collection process and the interviews were recorded and transcribed afterwards. Content analysis was adopted based on the different case companies and around the central topics of this study. The data collection results 
with a requirement list were sent back to the interviewees for validation. In addition to qualitative data from the case studies used as the primary source, secondary data were also collected using a cademic publications, Internet sources and corporate materials from both internal and externalorganizational sources.

For data a nalysis, manufacturing ecosystem implementation strategies [36] were adopted. This research includes three main parts. In the first part, different portaltypes for cloud manufacturing ecosystems are summarized. It is necessary to consider the approach of different partners' collaboration in the ecosystem and ensure that the collabo ration can meet the customer's needs. Secondly, a prototype of a CloudEcosystem platform is developed to support various activities in the manufacturing ecosystem. The cases can provide empiricalevidence for grounded theory building [31] in the cloud manufacturing ecosystem domain, and they illustrate the requirements for collaborative manufacturing portals from a practitioner point of view. As an additionalevaluation part, a pilot is implemented to demonstrate some key features of the CloudEcosystem: (1) steel parts for decorative items, architectural panels, and (2) custom made steel parts for roofs.

In order to check the results of the data analysis and the defined requirements, a validation round was performed by a pplying adapted axiom atic design principles [67]. Axiomatic design (AD) was initially used for product development but it has also been applied in software engineering domain [69]. The design parameters (DPs) were selected based on functional requirements (FP), which were defined based on customer needs (CNs), namely the requirements for cloud manufacturing ecosystems (presented in Table 2) in this particular study. The design concept of portal types would be considered as ideal collaboration models when the independence design parameter completely satisfies the requirements of the ecosystem. As an objective, two axioms should be fulfilled in the design: (A1) independence of functionalrequirements interacting with each other, and (A2) information content of the design should be minimized.

In order to understand cloud manufacturing ecosystems, the strategic and technical requirements for collaborative manufacturing portals were collected in interviews. This is also the first step to perform the AD. The respondents also pointed out the requirement priority levels from ' $1-3$ ', where 1 means high priority, 2 means medium priority, and 3 means do these later. Table 2 outlines the most important and necessary requirements. 
Table 2. Requirements for Cloud Manufacturing Ecosystems

\begin{tabular}{|l|l|l|l|}
\hline ID & Requirements & Sources & Priority \\
\hline RQ1 & Support consistent information and communication a mong distributed partners & C1,C2,C3 & 1 \\
\hline RQ2 & Provide a network to support partners' heterogeneity & C1,C2 & 1 \\
\hline RQ3 & Support partners in keeping their policies independent while cooperating through & C1,C2,C3 & 2 \\
\hline RQ4 & Support engineering collaboration and digitized product design activities & C3 & 2 \\
\hline RQ5 & Integrate multiple data sources & C3 & 2 \\
\hline RQ6 & Provide a security solution to ensure partners' data and privacy & C3 & 3 \\
\hline
\end{tabular}

\subsection{Research Analysis}

By analysing the capabilities of the three case companies, it is interesting to notice that they a re active actors and can fulfil specific tasks in the sheet metalmanufacturing ecosystem. The sheet metalmanufacturing ecosystem covers the main the sheet metalproduction stages, from design to mass production. The focus a rea is the communica tion between these actors during the offering and order fulfilment stages. Material movements and inventory handling related functiona lity were not a concern as companies use ERP systems for these activities.

\subsubsection{The conceptual framework design}

In order to provide customers with comprehensive services, the ecosystem should include several essential elements, such as R\&D services for design and prototyping, tool design and manufacturing, and demand-based production and facilities. Different actors a re involved and working together to fulfil these tasks, namely distinctive manufacturing brokers, independent manufacturers, product designers, customers, and IT solution providers.

The centralized control enterprise is named manufacturing broker (and can also be a factory manager). It is responsible for collecting customerorders, designing a process model, describing the manufacturing process and then assigning appropriate manufacturing companies (in this scenario, they are called partner factories and machine providers) to accomplish the manufacturing processes. The manufacturing broker is mainly responsible for the order fulfilment, and a lso designs all the dynamic cross-orga niza tionalma nufacturing processes, and a set of existing partner 
factories performs the actual tasks in each production step. Each manufacturer can perform different manufacturing processes according to their own capacities and capabilities.

Product designers a re responsible for integrating customer requirements and different product properties together to make the correct decisions on production. Product designers can reuse patterns and design rules from previous work and improve upon prior art and the work of others. They can also create new products for the marketplace to be licensed and used in the future. On the other hand, end customers can also place orders directly to the manufacturing enterprises with user-created design or customize existing design. They can also compare ma nufacturability options. IT solution providers deliver the foundation and solutions for collaboration in the cloud manufacturing ecosystem. However, providers are not necessarily separate organizations. Manufacturing enterprises can act as IT solution providers as well. Figure 3 summarizes the main actors' groups and the associated high-level use case.

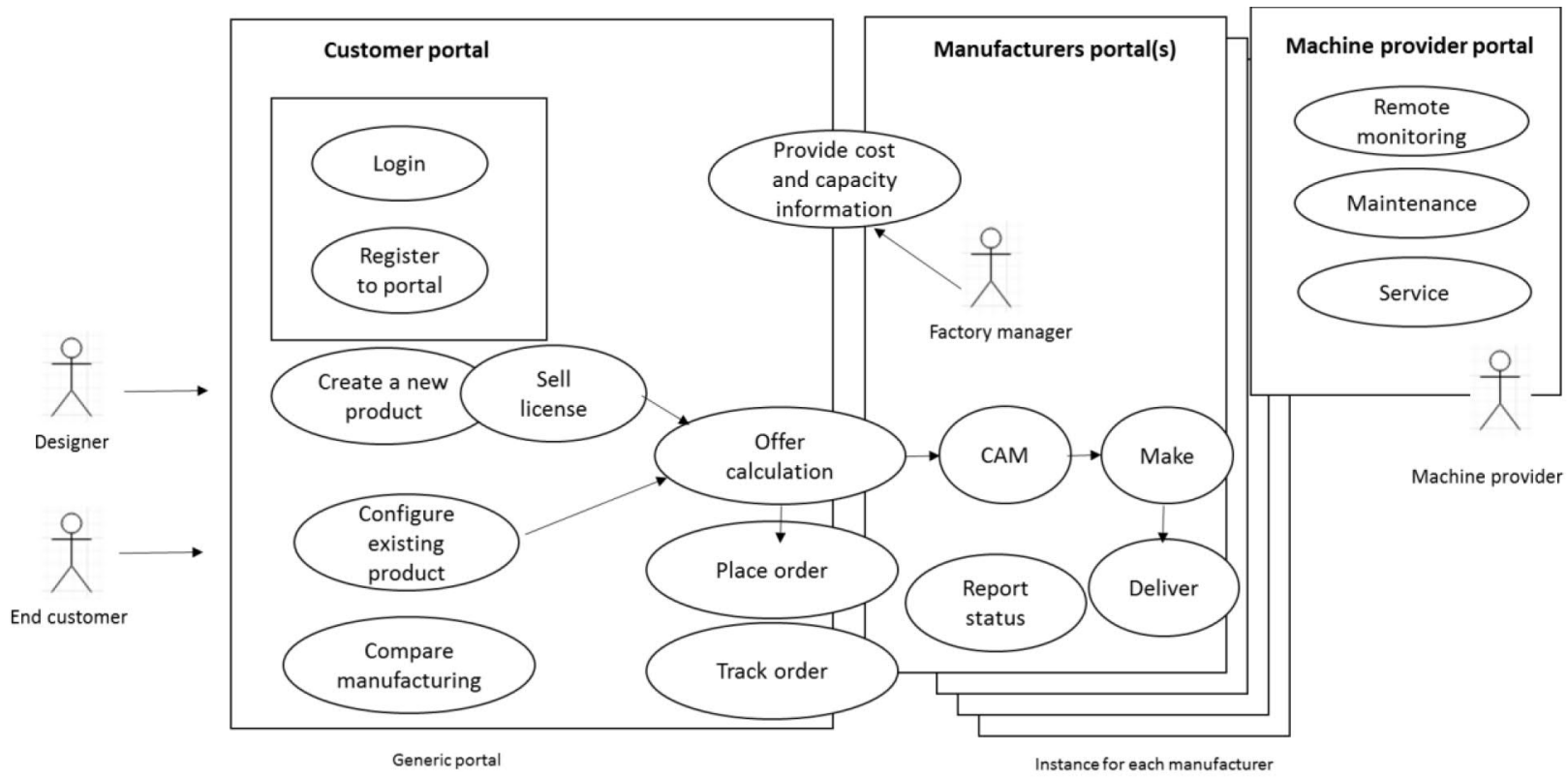

Figure 3. High level of use cases and examples of functionalities

To enable collaboration among all the actors and to help the companies make the right business decision about a particular opportunity, the cloud manufacturing ecosystem needs four main functional areas: design management, order management, partner management, and process management. Figure 4 illustrates a conceptual approach for a cloud manufacturing ecosystem. 
Cloud Manufacturing Ecosystem

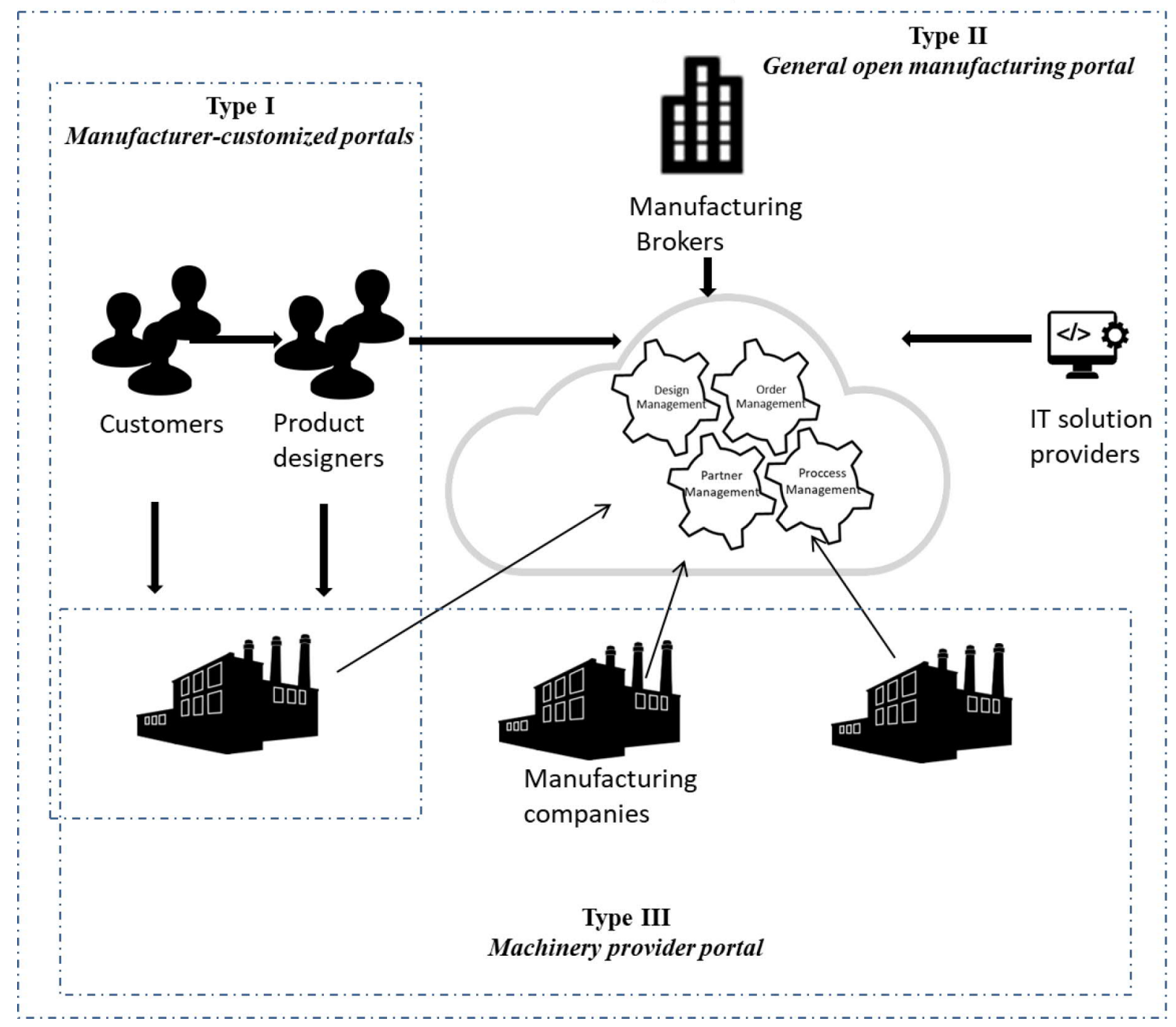

Figure 4. Cloud manufacturingand manufacturing ecosystem portals

In this cloud manufacturing ecosystem, a key issue is to understand the dynamic of interactions and communications in the information and operation asymmetry environment. Game theory could be applied as a powerful theoretical tool for modelling and analysing the interactions among all the participants. In the game theory mechanism, different agents have different roles and strategies. When the manufacturing brokers assign appropriate partners to specific manufacturing tasks and processes, they need to consider how to manage and optimize the collaboration activities. Some partners may have variously competitive and cooperative relationships, depending on their capabilities, resources, services, and products. The manufacturers a re responsible for ma inta ining and monitoring proper machinery use. During the interviews, agents and their roles were planned. The potentialagents and their roles for this ecosystem 
are listed in Table 3. The business decisions are also elaborated associated with each roles. Formal mathematical modelling related to game theory was not conducted.

Table 3. List of a gents and roles.

\begin{tabular}{|c|c|c|c|}
\hline Agent & Roles & Primary business decisions & Competition \\
\hline Manufacturing broker & Content provider & $\begin{array}{l}\text { - } \text { Marketing } \\
\text { - } \quad \text { Service a greement } \\
\text { - } \quad \text { Pricing scheme }\end{array}$ & $\begin{array}{l}\text { Manufacturing companies } \\
\text { serving directly to end- } \\
\text { customers }\end{array}$ \\
\hline Manufacturing companies & Service provider & 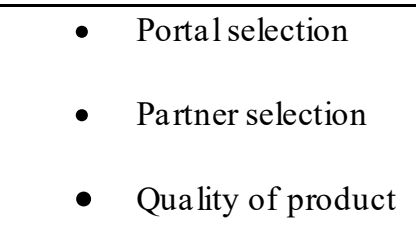 & $\begin{array}{l}\text { Manufacturing brokers and } \\
\text { other manufacturing } \\
\text { companies }\end{array}$ \\
\hline Product designers & Service provider & $\begin{array}{l}\text { - Portal selection } \\
\text { - } \quad \text { Qua lity of design }\end{array}$ & $\begin{array}{l}\text { Serving end-customers, } \\
\text { manufacturing brokers and } \\
\text { companies, competing with } \\
\text { other product designers }\end{array}$ \\
\hline IT solution providers & Platform operator & $\begin{array}{l}\text { - } \text { Portal development } \\
\text { - } \quad \text { Portal maintenance }\end{array}$ & $\begin{array}{l}\text { Gatekeeperpower to other } \\
\text { portalusers }\end{array}$ \\
\hline End customers & Service consumer & $\begin{array}{ll}\text { - } & \text { Customer } \\
\text { - } & \text { Pricing scheme } \\
\text { - } & \text { Service agreement }\end{array}$ & $\begin{array}{l}\text { Creating demand for the rest } \\
\text { of the companies. In more } \\
\text { complex situations, } \\
\text { manufacturers may operate } \\
\text { as end customers as well. }\end{array}$ \\
\hline
\end{tabular}

\subsubsection{Portal types for cloud manufacturing ecosystems}

Each case company was analysed based on its role in the manufacturing ecosystem and its cloud-based platform for its business. The case companies demonstrated how the portals could improve their business and their strategies in the sheet metalmanufacturing ecosystem. These portals can help companies move beyond the boundaries of each partner and communicate through the entire collaboration process. The collaborative manufacturing process will be optimized by enabling the integration of $\mathrm{R} \& \mathrm{D}$ activities, ordering, factory selection, forecasting, monitoring, and collaboration during runtime. 
- $\quad \mathrm{C} 1$ is putting effort into its manufacturing facilities management on an international scale. In order to ma nage its global operations and expand its market, this portal includes a broad range of tools of financial mana gement, such as business plan and control, and a lso partner ana lysis.

- $\quad \mathrm{C} 2$ is outsourcing some manufacturing activities which are beyond its effective scope. Therefore, C2 is focusing on the outsourcing relationship management and production and operation management. This portal is integrated with MES (manufacturing execution system), and includes functionalities such as tracking machine utilization, cutting tool management, machine inspection, and so on.

- C3's business purposes are twofold: enabling internal communication on a geographically dispersed scale and supporting external collaboration with other partners and customers. This portal encompasses features such as the tracking of tasks, a mongst others. The customers can access the order information and track the production process as well.

Based on the case analysis, three main types of portals have been identified to examine the cloud manufacturing ecosystem. Different focal companies host each type of ecosystem portal and have different positions in the value chain. These three portals are constructed in the cloud manufacturingecosystem, as shown in Figure 3:

- $\quad$ Type I: Manufacturer-customized portal(forcase C3)

This portal mainly concentrates on the optimization of the relationship between manufacturer and customers. It transforms the supply chain into a dynamic network. This portal is hosted by a manufacturer and serves its customers. Generally, no other participants are involved in the transactions. This particularmanufacturerhas full control over the value chain. The cloud-based infrastructure is implemented to fulfil the requirements of automatization and systematization in the communication process. The process is initiated by placing an order by the customers. For instance, customers can directly use parametric products, which are licensed designs. Customers can also upload their own models to get an instant quote. Customers can buy products that have existing designs or past order history. Product design services a re also available for customers when they request customized products.

- $\quad$ Type II: General open manufacturing portal(for case C2)

This portal provides manufacturing services for multiple participants with different roles. The end-users of this portal can be customers, manufacturing brokers, or manufacturing companies. In most cases, this portal is 
provided and supported by IT solution providers. However, manufacturing companies and brokers with sufficient IT capacities can also host this portal. Customers or manufacturing brokers can search for suitable virtualized manufacturing capabilities and capacities to complete a specific manufacturing task. The search criteria will be evaluated by past performance and current price, a mongst others. Technically, the cloud system can support multitenant architecture.

- Type III: Ma chinery provider portal (for case $\mathrm{C} 1$ )

In this type of portal, the main participants a re manufacturers providing similar machinery but located at different locations. In most cases, the users are manufacturers who require more machinery capacity. The manufacturers can offer specific services or capacities around the products/machinery. The services include capacity leasing services, remote monitoring, maintenance services, remote advisory services, and so on. When a manufacturer is not able to provide services to the customers in a certa in location, or in case machinery utilization is low, services and capacity may be leased to other portalmembers according to smart contracts.

Table 4 summarizes the host, purpose, benefits for host, users, and key functiona lity for each of the ecosystem portal types.

Table 4. Portal types for cloud manufacturing ecosystems

\begin{tabular}{|l|l|l|l|}
\hline & $\begin{array}{l}\text { Type I: Manufacturer- } \\
\text { customized portal }\end{array}$ & $\begin{array}{l}\text { Type II: General open } \\
\text { manufacturing portal }\end{array}$ & $\begin{array}{l}\text { Type III: Machine } \\
\text { provider portal }\end{array}$ \\
\hline Case Company & \multicolumn{1}{|c|}{ C3 } & \multicolumn{1}{|c|}{$\mathrm{C} 2$} & \multicolumn{1}{c|}{ C1 } \\
\hline Host & Manufacturing company & $\begin{array}{l}\text { Manufacturing broker / } \\
\text { Manufacturing company /IT } \\
\text { solution provider }\end{array}$ & Manufacturing company \\
\hline Purpose & $\begin{array}{l}\text { Increase sales by customized } \\
\text { services and selling parametric } \\
\text { product; }\end{array}$ & $\begin{array}{l}\text { Make profit by selling virtual } \\
\text { capacity; } \\
\text { Increase competition by } \\
\text { establishing partnership }\end{array}$ & $\begin{array}{l}\text { Increase capacity utilization by } \\
\text { enabling machine capacity } \\
\text { leasing and fractional } \\
\text { ownership of assets }\end{array}$ \\
\hline
\end{tabular}




\begin{tabular}{|c|c|c|c|}
\hline & $\begin{array}{l}\text { Simplify customer relationship } \\
\text { by reducing offering and } \\
\text { handling time }\end{array}$ & & \\
\hline Benefits & $\begin{array}{l}\text { - Keeping company identity and } \\
\text { customization according to the } \\
\text { manufacturer } \\
\text { - Automated price/cost online } \\
\text { calculators } \\
\text { - Cost and time savings with } \\
\text { online CAD/CAM and order } \\
\text { placing mechanisms } \\
\text { - Automated order flow systems }\end{array}$ & $\begin{array}{l}\text { - Possibility to increase customer } \\
\text { basis } \\
\text { - Platform for automated } \\
\text { price/online cost calculator } \\
\text { - Cost and time savings in market } \\
\text { communication } \\
\text { - Automated order flow system } \\
\text { - Possibility to choose from a } \\
\text { variety of manufacturers to make } \\
\text { an order } \\
\text { - Evaluation of design in terms of } \\
\text { manufacturing prices }\end{array}$ & $\begin{array}{l}\text { - Providing a marketplace to } \\
\text { connect manufacturers } \\
\text { - Eliminating the idle time of } \\
\text { production and improving } \\
\text { productivity } \\
\text { - Increasing the return on } \\
\text { capital investment of high-tech } \\
\text { machines }\end{array}$ \\
\hline Users & Customers, product designers & $\begin{array}{l}\text { Manufacturers who need small } \\
\text { batch production }\end{array}$ & $\begin{array}{l}\text { Machine owners who lack of } \\
\text { machinery capacity or are not } \\
\text { able to provide services }\end{array}$ \\
\hline Functionality & $\begin{array}{l}\text { Offer placement, order handling, } \\
\text { product design }\end{array}$ & $\begin{array}{l}\text { Intelligent pricing, payment } \\
\text { handling, product designs } \\
\text { selling/sharing }\end{array}$ & $\begin{array}{l}\text { Capacity planning, } \\
\text { performance monitoring }\end{array}$ \\
\hline
\end{tabular}

\subsection{Requirements validation}

In order to evaluate the portal types, the design parameters of this portal types are mapped with the requirements defined by the interviewees in Table 2. For each selected RQ, a DP is developed to match 'what we want to achieve' with 'how to achieve it'. However, the highest level of RQs and DPs should be decomposed into a lower level to describe the business processes and to reflect the real problems of implementing cloud manufacturing ecosystem.

Figure 5 shows the relationships between RQs and DPs separately for evaluation. This mapping and decomposition process can help researchers to understand the objectives of the whole design. Processing FPs and DPs is an interactive 
process. Definition of RFs is driven by objectives of collection requirements, describing each in a way that users have common understanding of the short labels and ensuring that Axiom 1 will be fulfilled. This process should help reducing the complexity of the upstream process. Zig-zag tables and othervisua lizations can help conducting this, but in the end the process is iterative.

\begin{tabular}{|c|c|c|c|c|c|c|c|c|c|c|c|c|c|c|c|}
\hline $\begin{array}{l}\mathbb{X}=\text { impact } \\
(0=\text { no impact }\end{array}$ & 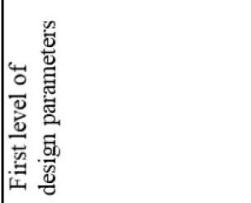 & & 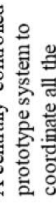 & & & & & 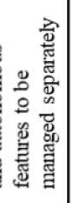 & & 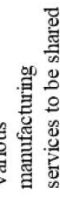 & & & & & 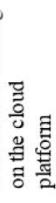 \\
\hline $\begin{array}{l}\text { First leve } \\
\text { requireme }\end{array}$ & $\begin{array}{l}\text { Second level of } \\
\text { requirements }\end{array}$ & 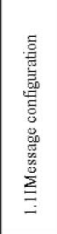 & 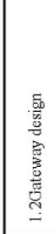 & 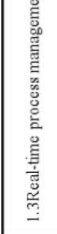 & 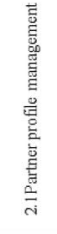 & 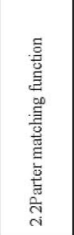 & 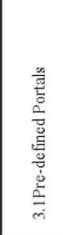 & 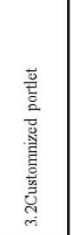 & 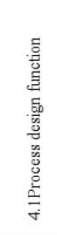 & 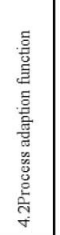 & 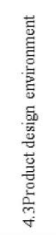 & 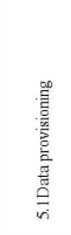 & क्ष்̃ & 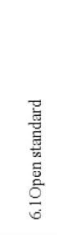 & 产 \\
\hline & 1.1 Support information integration & 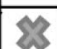 & (0) & (0) & () & (0) & (0) & (0) & (0) & (0) & (0) & (0) & (0) & (0) & () \\
\hline - & 1.25upport communication & (0) & $\mathbb{2}$ & (0) & (0) & (0) & (0) & (c) & (0) & (0) & (2) & (0) & (2) & (0) & (2) \\
\hline & 1.3Support business process & (1) & () & X & (0) & (c) & (0) & (c) & (1) & (0) & (2) & (0) & (1) & (0) & (2) \\
\hline & .1Patner search & (0) & (0) & (0) & $x$ & (1) & (0) & (1) & (1) & (2) & (2) & (0) & (2) & (0) & (1) \\
\hline $\begin{array}{l}\begin{array}{l}\text { Provide a } \\
\text { supportp } \\
\text { heterogen }\end{array} \\
\text { hes }\end{array}$ & 2.2Partner reconmendation & (0) & (0) & (0) & (0) & $\mathbb{X}$ & (0) & (0) & (0) & (0) & (2) & (0) & (0) & (0) & (-) \\
\hline $\begin{array}{l}\text { RQ3 } \\
\text { Support partners in }\end{array}$ & 3.1. Standard protocol & (0) & (0) & (0) & (c) & (c) & $\mathrm{x}$ & (c) & (0) & (2) & (2) & (0) & (2) & (0) & (2) \\
\hline $\begin{array}{l}\text { Keep their policies } \\
\text { independent while } \\
\text { cooperating through } \\
\text { mutually agreed } \\
\text { protocols }\end{array}$ & 3.2.Enable customization & (0) & ○ & (0) & (0) & (2) & (0) & $\mathbb{x}$ & (0) & () & () & () & (2) & (0) & (0) \\
\hline RQ4 & $\begin{array}{l}\text { 4.1Facility the manufacturing } \\
\text { ccturities }\end{array}$ & (0) & (0) & (0) & (0) & (0) & (0) & (2) & $\mathbb{X}$ & (2) & (2) & (0) & (0) & (0) & (2) \\
\hline & 4.2Establish collaboration & (0) & (0) & (0) & (0) & (0) & ( ) & (2) & (0) & $\mathrm{X}$ & (2) & (0) & (2) & (0) & (2) \\
\hline $\begin{array}{l}\text { ized pr } \\
\text { ities }\end{array}$ & 4.3Support product designers & (0) & (1) & (0) & (0) & (2) & (0) & (c) & (1) & (2) & 3 & (0) & () & (0) & (1) \\
\hline & :.10pen standards & (0) & (0) & () & () & (2) & (0) & (2) & (1) & (ㅇ) & (0) & 《 & () & (0) & (2) \\
\hline sources & 2.2Interoperabality & (0) & (0) & (2) & (2) & (2) & (0) & (2) & (2) & (0) & (0) & (0) & $\sqrt{2}$ & (0) & (2) \\
\hline RQ6 & 6.1. Security & (0) & (0) & (1) & (1) & () & (0) & (1) & (0) & (ㅇ) & (1) & ( ) & (1) & $x$ & (1) \\
\hline $\begin{array}{l}\text { Solution to ensure } \\
\text { pattners' data and } \\
\text { privacy }\end{array}$ & cy & (ㅇ) & (0) & (1) & (1) & (2) & ( & (1) & (0) & (2) & (1) & (0) & (2) & (0) & $x$ \\
\hline
\end{tabular}

Figure 5. Evaluation based on fulfilment of RQs that have been satisfied in all design parameters (high level summary)

Besides the evaluation results based on the AD principles, this research explains how portals can facilitate business activities within cloud manufacturing ecosystems. Thus, the present paperprovides both theoretical implications and managerial implications for the manufacturing industry.

\section{Research Findings}


These findings mainly focus on providing insights into how the case companies adapted to the cloud manufacturing ecosystem by implementing portals. The description in the previous section provides a ba seline understanding of the possibilities of different portals and also the requirements of cloud manufacturing ecosystem implementations. Based on the feedback from the case companies, the cloud manufacturingecosystem is complex and hard to predict because many interdependent actors are involved. They cooperate and compete by sha ring resources and capabilities. Each of the actors has their own interests, roles and relationships with others. Accordingly, a prototype system is created to capture and make sense of all the activities in this dynamic ecosystem. Therefore, an accessible and actionable design and technicalimplementation of the prototype system is discussed in this section.

\subsection{Prototype design}

CloudEcosystem is a prototype of a portal to support the cloud manufacturing ecosystem in the context of sheet metal manufacturing. Because the characteristics of each portal type vary, the functionalities and requirements for implementation are different. However, these three types of porta ls have some common functionalities, including user management, asset management, and order management. Similar software components can be used in both configurations. From the software engineering perspective, different functionalities are needed for different types of portals. For instance, each manufacturer may have their own customized portal (Type I portal implemented by C3) and offer functiona lity for order-fulfilment. On the other hand, a generic open manufacturing portal (Type II portal implemented by C2) can query the prices from each factory and offer visibility to the end-customer, not only costwise, but also in terms of production. This a rchitecture running on the cloud platform enables various configura tions. Figure 6 highlights the core features designed for the CloudEcosystem prototype. 


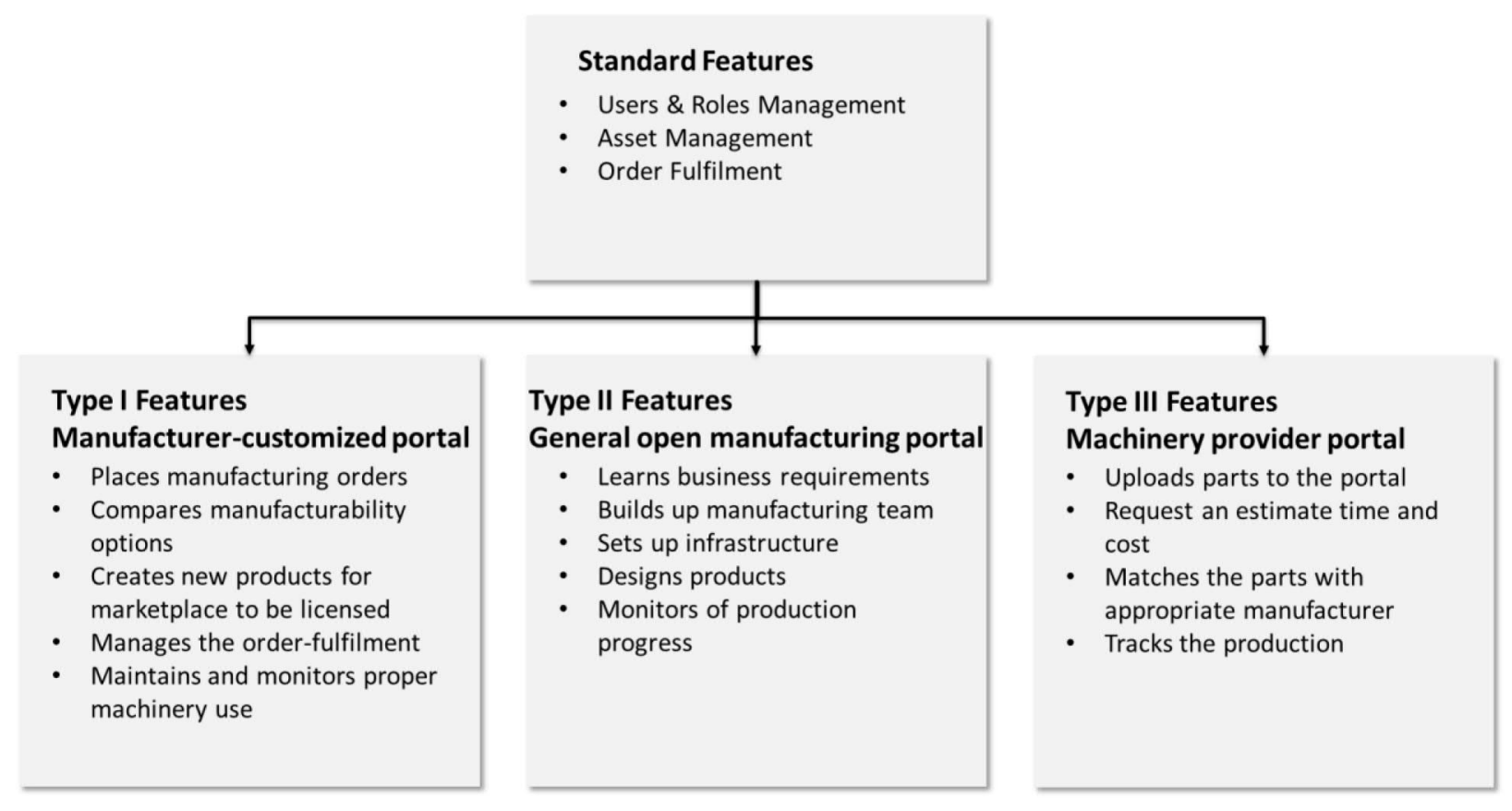

Figure 6. The generic functionalities of different types of portals

In this cloud manufacturing ecosystem, a multitenancy structure is implemented. This structure allows tenants who have a common interest in sharing the same core of data configuration and functionalities among several server computers. However, they can still control their manufacturing cloud architecture based on their own needs and can keep all manufacturer related sensitive data in a separate location as a standalone instance. Figure 7 determines how needed elements are linked to different portal types. This simplified entity-relationship domain model is designed as the main part and extended part. The left part of the diagram shows the main tables that need to be stored centrally. The right part includes user-specific elements based on user types and business needs. Each manufacturer maintains them in the ecosystem case. For example, support for material handling rela ted events a re minimal. Each manufacturer should provide an up to da te list of available raw materialsheets with pricing. Stock levels and not stored in the portal and it is responsibility of the provider to keep the availability information up to date. Movement from manufacturer to customer is tracked on the portal delivery section. Otherwise stockholding functionality is not implemented. 


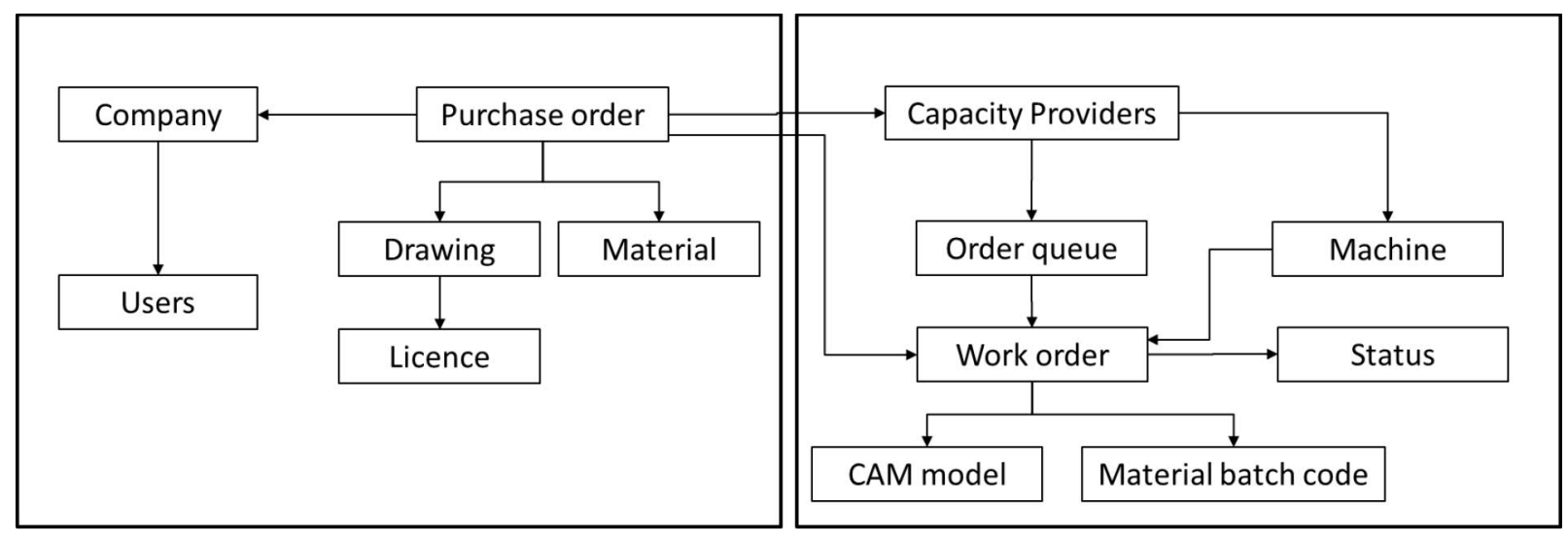

Figure 7. Example of a domain model for different portals.

\subsection{Technical implementation}

Although the cloud manufacturing ecosystem is explained at the conceptual level, its practical implementation is still problematic. It is imperative to have an IT infrastructure to support all cloud manufacturing activities and operations technically. This section describes a solution for CloudEcosystem architecture.

There are some general requirements to implement the portal to support cloud manufacturing. Firstly, it must provide timely and consistent information to each actor with different information views. Secondly, it must accommodate heterogeneities, and at the same time, set up efficient communication among the various actors. Last but not least, it must be extendable for future needs when there are new demands from actors. According to these general requirements, the architecture presented in this research can be designed as a component-based architecture with three layers, as explained in Figure 8. By using the SOA and REST concept, the software components are converted to services and consumed by different business events. This architectural framework should support the main activities of the cloud manufacturing ecosystem. It makes use of modern IT to form a cloud manufacturing ecosystem, which responds agilely to changing market demands. 


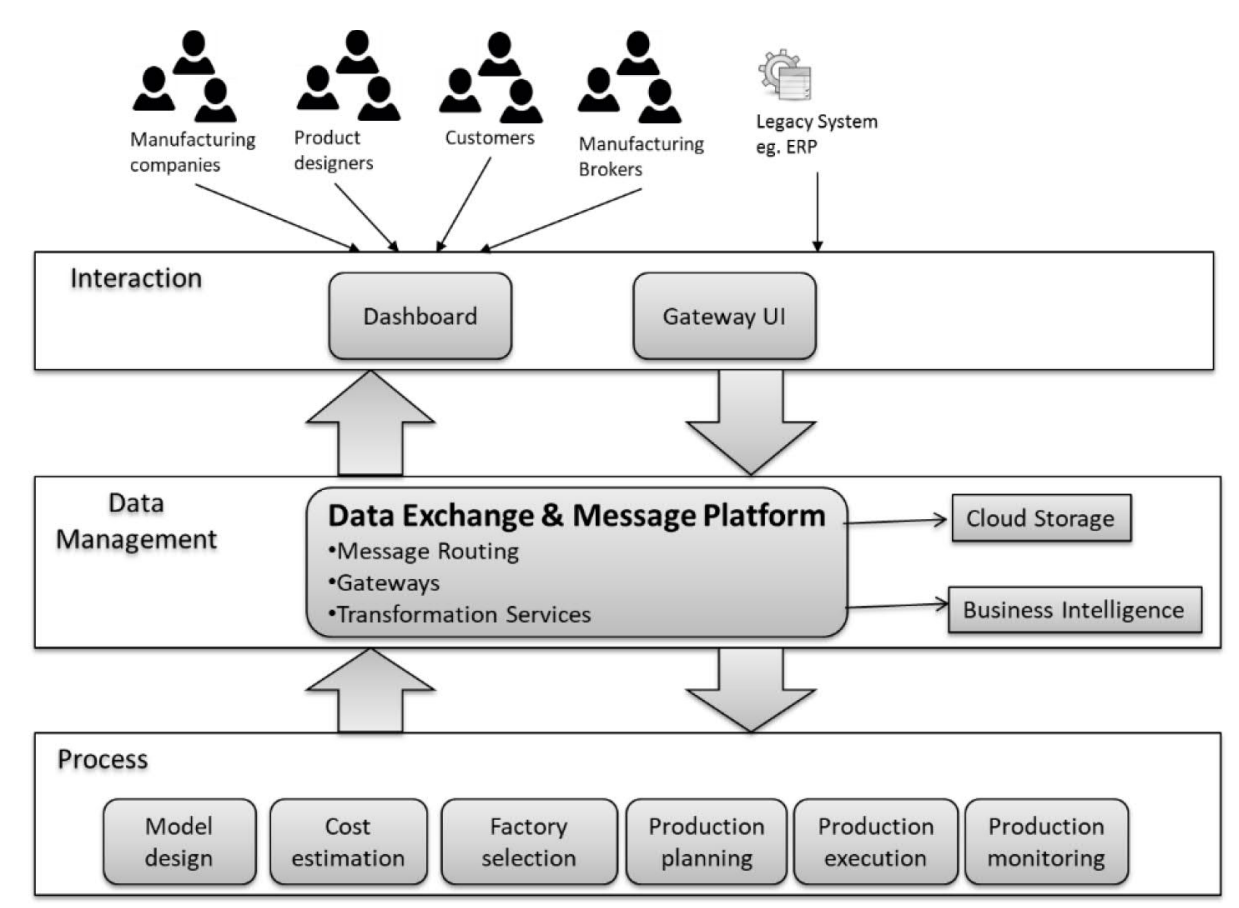

Figure 8. The components of CloudEcosystem architecture

Beca use the functiona lity of the cloud manufacturing ecosystem is comprehensive covering items from product design to pricing and operations, the portalstructure should be modular. The portal is based on a distributed architecture, and is constructed of different components from three layers to achieve integration, namely the interaction layer, data management layer, and process layer:

- The interaction layer supports user interaction and communication with external systems. In the interaction layer, the dashboard is the entry point for users to the portal. The dashboard can provide a signal view for all the partners. All the functionalities of the cloud manufacturing ecosystem are visualized on this dashboard, such as product model design, model confirmation, factories comparison, etc. The other external systems (e.g. legacy or ERP systems) will be integrated into this platform through Gateway UI. Externalsystems will deliver valuable real-time information such as an order from a customer and the current status of production.

- The data management layer provides an internal component communication and data handling service. The primary purpose of data exchange and message platform is to convert external data and realise the integration functionalities. The cloud storage is a centraldata store and it supports the virtualization and different types of data storage. The use of cloud-based data storage provides high scalability concerning data throughput and 
storage capacity. In order to achieve data sharing and integration, STEP standard is adopted to agree on how data will be reused across the partners [18].

- The process layer offers reusable process components to execute the business functionalities. All business activities are collected and analysed. This layer orchestrates all the interaction in a cloud manufacturing ecosystem.

This distributed architecture offers many advantages compared to a centra lized approach. It allows more components to integrate more ea sily and a dapt processes quickly a susiness grows and requirements change. This architecture has a high degree of scalability and availability because of its ea sily expandable components and duplica ted deployment approach. For instance, if one component unexpectedly fails, a notherinstance can still perform the ta sk at hand.

\subsection{Validation of design - Use case example of CloudEcosystem platform}

An example configuration of a portal is a case of an innovative and open-source platform for rapid and distributed manufacturing. This instance of CloudEcosystem platform is hosted by one of the case companies (case company C3). In this example, a cloud-based subcontracting platform is introduced to demonstrate laser cutting services in the sheet metalmanufacturing industry, such as (1) steel parts for decorative items, architecturalpanels, and (2) custom made steel parts for roofs. The components are made to order according to customer mea sures, i.e. products are parametric. By providing all manner of services and content on these platforms, this ca se company a ims to crea te a comprehensive ecosystem in which end customers, product designers, manufacturingengineers and production operators across the production process can simulate critical and complicated decisions before acting. Moreover, other competitors can hardly rival but also receive benefits from the ecosystem.

This example portalbelongs to type I, according to the identified portals. This manufacturing company acts a s both a service provider that supports design and production and also as a technology provider that hosts and controls the platform. By using this manufacturing portal, the end customer can create and upload models and the laser cutting design, and then select suitable material, colour, and manufacturer to manufacture the products. This portal can fulfil the requirements of on-demand manufacturing in case of decorative steel panels. The following services a re provided across manufacturing processes as follows: 
- In order to improve the design process and ensure the product models a re manufacturable, third-party product design services and automatic/manualmodel validations services in CAM are both provided. The geometry and other parameters are ava ilable to customers with limited edits. Parametric products such as steel parts for roofing can be configured on-line by the web user interface. For engineering type of products, such as architectural decoration panels, a 2D shape file can be imported to online editor and merged with a panel product to create a unique instance of a product.

- In order to ensure that best-fitted solutions are selected, customers can quickly generate cost estimation services that are based on potential features (i.e. delivery time, company, factory, and machine), and compare possible solutions before actually placing an order. The calculation is based on pre-defined formulas and values stored in the centralized portal.

- In order to provide flexibility to customers, they can receive order confirmations either from the internal system by using a default setting or from the external production planning system by using a customized setting.

- In order to increase the transparency and visibility of the supply chain, the status of the order and updated information about the production can be delivered to customers in real-time and kept in the portal. An invoicing service is also provided with features of creating and sending invoices, and tracking payments.

Figure 9 shows screenshots of the user interface from the initial prototype version. It includes user authentication, product model design management (crea te, upload and edit), and order mana gement. 
Authentication

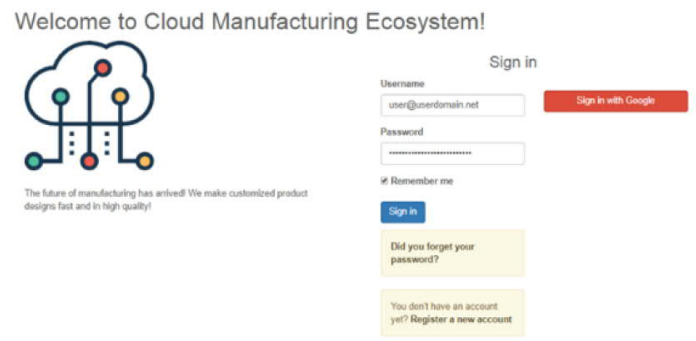

Available models for manufacturing

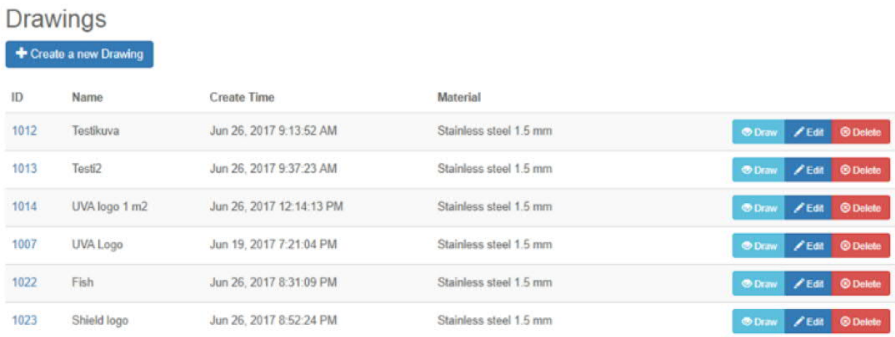

Order confirmation and supplier evaluation

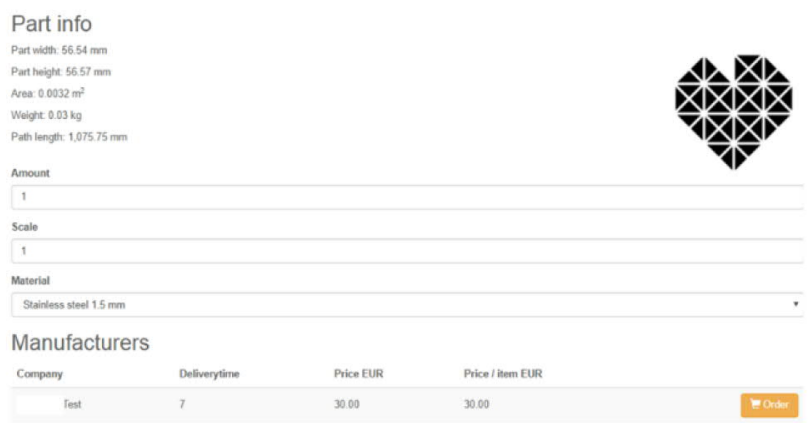

Figure 9. User interface screenshots of a manufacturing portal

Different business tasks, transactional services, and communications a re supported by different softwa re components that are implemented by using SOA and SaaS. In this prototype, the software components a re executed in a distributed environment. Figure 10 illustrates an example of the communication flow between the customer portaland the service provider. This information is needed to complete the tasks from a cost estimate request to order completion.

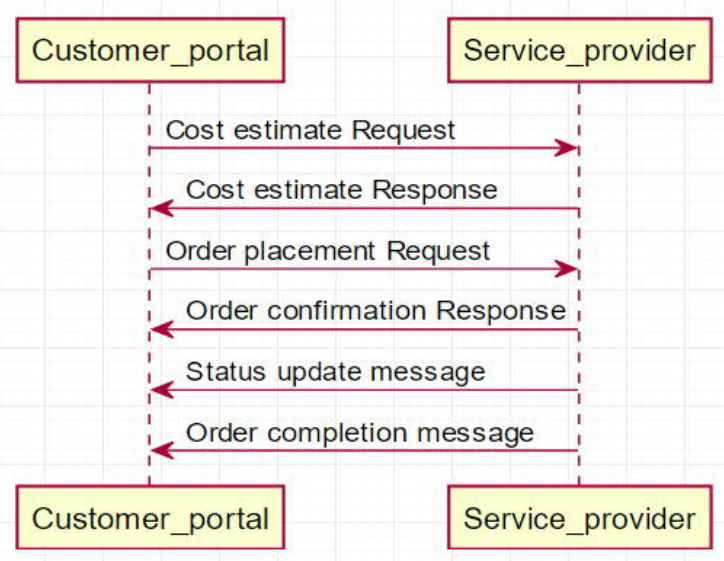

Figure 10. UML sequence dia gram of completing an order. 
The described use case was implemented with CloudEcosystem and connected to a C1 company order-fulfilment process. A designer was introduced for product parameterization possibilities and cost accounting was prepared for pricing. The system was piloted among the companies from testing various designs and how cost estimatorbehaved all the way to manufacturing a small set of para metric and custom design products. The experimentation showed the power of the system for automated design and pricing related communication as this part is done in the portal and it reduces communication to manufacturer conducting laser cut and bending. Interface built to a CAM system also provided an automated transfer of orders to queue. The test implementation did not provide solution for marking the materials or packaging and shipment. An evaluation interview was conducted after piloting the system. This was done in a group where all participants' roles attended. The main benefits identified for the system were: (1) faster communication between product OEM and the manufacturer to get an up to date quote, (2) reduced time to handle order-information, (3) possibility to have parametric designs. The main challenges identified were (1) each ERP and $\mathrm{CAM} / \mathrm{MES}$ connection is factory specific, (2) introducing a large number of parametric products requires product management, (3) pricing of materials should be kept up to date on a weekly basis. As several manufacturers and designers would be using the portal, there was a worry about lot sizes getting smaller and affecting the productive capacity of lines. Understanding this kind mechanism would need a real market test. Figure 11 shows a sample of decorative panelmanufactured during the piloting. 


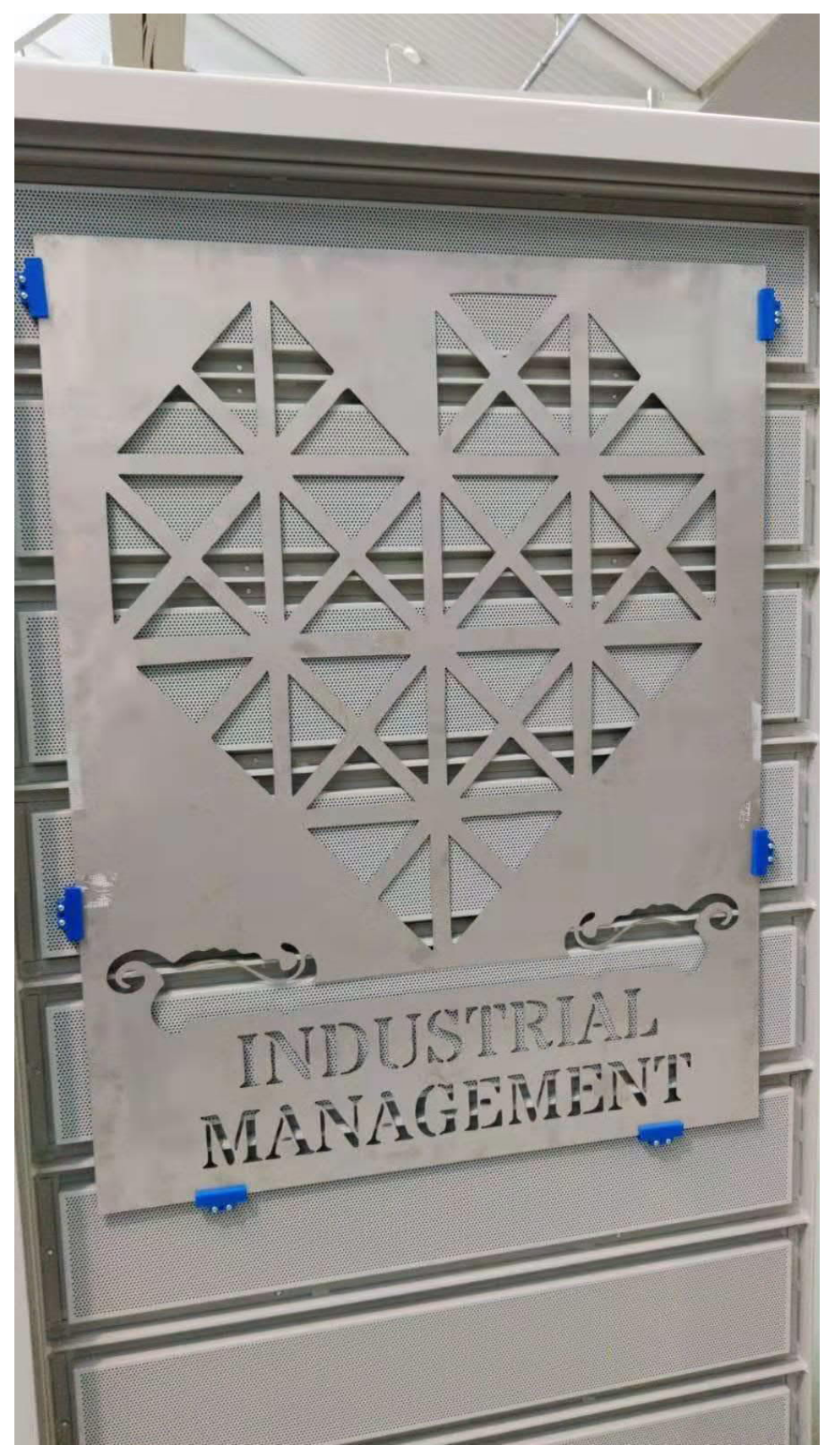

Figure 11. A sample of decorative panelmanufactured during the piloting.

\section{Discussion}

The manufacturing industry is becoming more and more complicated: progressively extending on a global scale and subject to increasing demands from customers. These new requirements stimulate manufacturers to increase their operational efficiency and flexibility. New digital technologies are being deployed in the manufacturing industry to 
enhance transparency and collaboration among manufacturers, and help manufacturers to develop and operate effectively in a flexible ecosystem. However, current research is still limited regarding how to achieve and implement manufacturing ecosystems with advanced technologies. Based on qualitative data from three sheet metal manufacturing companies, the findings in this research suggest an approach to implement ing a cloud manufacturing ecosystem.

\subsection{Theoretical implications}

This research is focused on connecting the recent development of two research doma ins, namely business ecosystems and cloud manufacturing. The characteristics of cloud computing, such as sca lability, flexibility, and being distributed, can support multitenancy infrastructures in the business ecosystem and its associated functionalities. The additive manufacturing ecosystem and community in IoT -ba sed sectors a re examples in the manufacturing environment. Many leading industrial solutions in different a spects, i.e. designing, devices, and engineering, have been built on the cloud to support, boost and expand the $3 \mathrm{D}$ printing industry and IoT industry. In order to support other traditional manufacturing processes such as cutting, milling, and assembly operations, a similar idea can be borrowed and implemented.

The concept of cloud manufacturing ecosystems is still new. It describes the multitude of manufacturing participants with one world, including customers, product designers, IT solution providers, manufacturing brokers, and manufacturers. It is also possible to include other participants who are willing to join a business ecosystem. In other words, the ecosystem is a comprehensive collaboration model. Co-evolution, co-creation, and co-delivery are inherent in the ecosystem. In order to increase the maturity of the ecosystem, it is critical to understand different collaboration models and different types of porta ls to support collab oration.

\subsection{Managerial implications}

The present study also provides several managerial implications for manufacturers intending to implement a cloud manufacturing ecosystem. Three different types of portal were designed in this research, namely manufacturercustomized portal, general open manufacturing portal, and machine provider portal. The portals support the essential requirements of three different types of user groups: customers, designers and manufacturers, respectively. The main challenges involve handling the interactions among these three user groups in a universal system. It is important to 
provide an effective and automotive coordinating mechanism for complete order fulfilment from product to process handling. When adopting cloud-based architectures as 'manufacturing as a service' (MaaS) in the manufacturing environment, users can share best practices with multi-tenant solutions, from shop floor level assets to management level entities. The three portal types introduced in this research are possible examples of implementing MaaS. The case companies improve the performance on a general level and increase flexibility by introducing the cloud manufacturing ecosystem.

The benefits of cloud manufacturing ecosystems can be considered from two aspects: market-related and organizational-related. For market reasons, cloud manufacturing ecosystems increase the activities/profit of collaborative businesses, help to cope with market turbulence, and explore new markets/new products. For organizational reasons, it increases the management level of manufacturing resources and capabilities from existing infrastructure. It also assists SMEs to enter the market and strengthen their position in supply chains.

\section{Conclusions}

The manufacturing industry is facing diverse impacts from different aspects, and manufacturing companies need to develop comprehensive manufacturing ecosystems. There are serval benefits from these future manufacturing ecosystems, such as the sharing of resources, ease of connecting with partners, and location flexibility. In this research, a cloud-based manufacturing ecosystem was proposed. Several case studies were analysed in order to illustrate how manufacturers face the adoption of cloud manufacturing ecosystems. Through interviews with experts in the manufacturing industry, cloud manufacturing ecosystem requirements related to implementation were identified. The CloudEcosystem was designed as a prototype to demonstrate the functionalities of the ecosystem. Later based on piloting, the experiences were collected from the participating company personnel. The results are by no means very comprehensive but give in sights what kind items are important in actualimplementation process.

A cloud-based manufacturing ecosystem is not completely the same as a manufacturing ecosystem or cloud manufacturing. Cloud-based technologies provide more opportunities for a typicalmanufacturing ecosystem in terms of more natural connection and integration because the cloud-based platform which enables data and message exchange. Moreover, specialized analytical a lgorithms are a vailable in the cloud to support business optimization. On 
the other hand, compared with cloud manufacturing, cloud manufacturing ecosystem s are more comprehensive and continually bring business opportunities into the industry. Therefore, manufacturing companies not only a chieve their business goals but also expand their business scope. Table 5 shows the comparison of cloud manufacturing and cloud manufacturing ecosystem terms from different a spects.

Table 5. Comparison of cloud manufacturing and cloud manufacturing ecosystem

\begin{tabular}{|c|c|c|}
\hline & Cloud manufacturing & Cloud manufacturing ecosystem \\
\hline Business purpose & $\begin{array}{l}\text { - } \text { Efficiency of the current } \\
\text { business operations }\end{array}$ & $\begin{array}{l}\text { - Co-evolve capabilities a round a new innovation } \\
\text { and collaboration or compete in the marketplace } \\
\text { - Distribution channel for manufacturers and } \\
\text { designers }\end{array}$ \\
\hline Business scope & $\begin{array}{l}\text { Marketplaces for suppliers and } \\
\text { customers }\end{array}$ & $\begin{array}{l}\text { Suppliers, customers, product designers, supporting } \\
\text { functions }\end{array}$ \\
\hline Business scale & $\begin{array}{l}\text { Micro: company level-mechanism } \\
\text { for improved efficiency }\end{array}$ & Macro: industry level - mechanism for competition \\
\hline Business purposes & $\begin{array}{l}\text { - To solve short-term operational } \\
\text { issues } \\
\text { - To fulfil dynamic requirements } \\
\text { in the market, capa city volume, } \\
\text { product mix, life-cycle }\end{array}$ & $\begin{array}{l}\text { - To create long-term advantages by using } \\
\text { networks } \\
\text { - To dominate the market by using position as a } \\
\text { distribution gateway }\end{array}$ \\
\hline
\end{tabular}

Establishing a large scale ecosystem is a very challenging task in reality as technology is not the only factor. Trust and relationship commitment are important for information sharing among manufacturers, but it is difficult to develop trust in a centralized framework [4]. Trust is needed among the participants and the technology provider as manufacturing portals handle designs, pricing and other manufacturing related IPR. Distributed manufacturing and digital ecosystems require mechanisms for intellectual property protection and mechanisms to support trust [68]. 
This paper has outlined for a framework of building cloud manufacturing ecosystems. $\mathrm{T}$ As the case scope only included three main cases, further study of other cases in the same industry is required to verify the patterns of platform strategy further. Furthermore, more industries should be tested in order to generalise the findings further. Moreover, these functiona lities should be developed and tested for practical use in real environments for all three portal types.

\section{References}

[1] Moore, J. F. (1998). The rise of a new corporate form. The Washington Quarterly, 21(1), 167-181.

[2] Gawer, A., \& Cusumano, M. A. (2014). Industry platforms and ecosystem innovation. Journal of Product Innovation Management, 31(3), 417-433.

[3] Borangiu, T., Trentesaux, D., Thomas, A., Leitão,P., \& Barata, J. (2019). Digital transformation of manufacturing through cloud services and resource virtua lization. Computers in Industry, 108, 150-162.

[4] Li, Z., Wang, W. M., Liu, G., Liu, L., He, J., \& Huang, G. Q. (2018). Toward open manufacturing: A crossenterprises knowledge and services exchange framework based on blockchain and edge computing. Industrial Management \& Data Systems, 118(1),303-320.

[5] Li, Z., Barenji, A. V., \& Huang, G. Q. (2018). Toward a blockchain cloud manufacturing system as a peer to peer distributed network platform. Robotics and computer-integrated manufacturing, 54, 133-144.

[6] Aghamohammadzadeh, E., \& Fatahi Va lilai, O. (2020). A novel cloud manufacturing service composition platform enabled by Blockchain technology. International Journal of Production Research, 1-19.

[7] Wang, B. (2018). The future of manufacturing: a new perspective. Engineering, 4(5), 722-728.

[8] Wang, Y., Zheng, P., Xu, X., Yang, H., \& Zou, J. (2019). Production planning for cloud-based additive manufacturing-A computervision-based approach. Robotics and Computer-Integrated Manufacturing, 58, 145157.

[9] Cui, Y., Kara, S., \& Chan, K. C. (2020). Manufacturing big data ecosystem: A systematic literature review. Robotics and Computer-Integrated Manufacturing, 62, 101861 .

[10] Ren, L., Zhang, L., Tao, F., Zhao, C., Chai, X., \& Zhao, X. (2015). Cloud manufacturing: From concept to practice. Enterprise Information Systems, 9(2), 186-209. 
[11] Wu, D., Greer, M.J., Rosen, D.W., \& Schaefer, D. (2013). Cloud manufacturing: Strategic vision and state-ofthe-a rt. Journal of Manufacturing Systems (JMSY), 32(4): 564-579. DOI: 10.1016/j.jmsy.2013.04.008.

[12] Tao, F., Zhang, L., Venkatesh, V. C., Luo, Y., \& Cheng, Y. (2011). Cloud manufacturing: A computing and service-oriented manufacturing model. Proceedings of the Institution of Mechanical Engineers, Part B: Journal of Engineering Manufacture, 225(10), 1969-1976.

[13] Zhang, L., Luo, Y., Tao, F., Li, B. H., Ren, L., Zhang, X., \& Liu, Y. (2014). Cloud manufacturing: A new manufacturing para digm. Enterprise Information Systems, 8(2), 167-187.

[14] He, W., \& Xu, L. (2015). A state-of-the-art survey of cloud manufacturing. International Journal of Computer Integrated Manufacturing, 28(3), 239-250.

[15] Liu, Y., Xu, X., Zhang, L., Wang, L., \& Zhong, R. Y. (2017). Workload-based multi-task scheduling in cloud manufacturing. Robotics and Computer-Integrated Manufacturing, 45, 3-20.

[16] Yang, J., Weber, C. M., \& Gabella, P. (2013). Enabling collaborative solutions across the semiconductor manufacturing ecosystem. IEEE transactions on semiconductor manufacturing, 26(4), 465-475.

[17] Chen, S., Fang, S., Peng, T., \& Tang, R. (2017). Operation Mode Study in Cloud Manufacturing Ecosystem. Procedia CIRP, 61(1), 347-352.

[18] Fatahi Va lilai, O., \& Houshmand, M. (2014). A platform for optimisation in distributed ma nufact uring enterprises based on cloud manufacturing paradigm. International Journal of Computer Integrated Manufacturing, 27(11), $1031-1054$.

[19] Aghamohammadzadeh,E., Malek, M., \& Valilai, O. F. (2019). A novel model for optimisation of logistics and manufacturing operation service composition in Cloud manufacturing system focusing on cloudentropy. International Journal of Production Research, 1-29.

[20] Henzel, R., \& Herzwurm, G. (2018). Cloud manufacturing: A state-of-the-art survey of current issues. Procedia CIRP, 72, 947-952.

[21] Helo, P., Boldosova, V., \& Toshev, R. (2017). Cloud-based manufacturing ecosystem-application development. In Proceedings of the International Conference on Industrial Engineering and Operations Management, Colombia, October, 2017.

[22] Rothschild, M. (1990). Bionomics: Economy as Business Ecosystem. Beard Books, Washington, D.C. 
[23] Nachira,F., Dini, P., \& Nicolai, A. (2007). A network of digital business ecosystems for Europe: Roots, processes and perspectives. European Commission, Bruxelles, Introductory Paper.

[24] Moore, J. F. (2006). Business ecosystems and the view from the firm. Antitrust Bulletin, 51(1), $31-75$.

[25] Wulf, A., \& Butel, L. (2017). Knowledge sharing and collaborative relationships in business ecosystems and networks: A definition and a demarcation. Industrial Management \& Data Systems, 117(7), 1407-1425.

[26] Rong, K., Lin, Y., Shi, Y., \& Yu, J. (2013). Linking business ecosystem lifecycle with platform strategy: A triple view of technology, application and organisation. International Journal of Technology Management, 62(1), 7594.

[27] Razavi, A. R., Krause, P. J., \& Strømmen-Bakhtiar,A. (2010, April). From business ecosystems towards digital business ecosystems. In 4th IEEE International Conference on Digital Ecosystems and Technologies (DEST), 2010 (pp. 290-295).

[28] Cenamor, J., Sjödin, D. R., \& Parida, V. (2017). Adopting a platform approach in servitization: Leveraging the value of digita lization. International Journal of Production Economics, 192, 54-65.

[29] Kress, P., Pflaum, A., \& Löwen, U. (2016, September). Ecosystems in the manufacturing industry. In 2016 IEEE 21st International Conference on Emerging Technologies and Factory Automation (ETFA), pp. 1-4.

[30] Camarinha-Matos, L. M., Afsarmanesh, H., Galeano, N., \& Molina, A. (2009). Collaborative networked organizations - Concepts and practice in manufacturing enterprises. Computers \& Industrial Engineering, 57(1), 46-60.

[31] Senyo, P. K., Liu, K., \& Effah, J. (2019). Digital business ecosystem: Literature review and a framework for future research. International Journal of Information Management, 47, 52-64.

[32] Eamonn, K. (2015). Introduction: Business ecosystems come of age. Business Ecosystems Come of Age. IFIP $243,399-406$.

[33] Eaton, B., Elaluf-Calderwood, S., Sørensen, C., \& Yoo, Y. (2011, April). Dynamic structures of control and generativity in digital ecosystem service innovation: The cases of the Apple and Google mobile app stores. London School of Economics and Political Science.

[34] Tsai, W. (2016). Analyzing the emergence of Alibaba group from business ecosystem perspective. The Journal of International Management Studies, 11 (2). 
[35] Panetta, K. (2017). 8 Dimensions of Business Ecosystems. Gartner. Available at: https://www.gartner.com/smarterwithgartner/8-dimensions-of-business-ecosystems/ [Accessed by 06/19/2018]

[36] Rasmus, R. \& McKinney, J. (2017). Manufacturing Ecosystems. Accenture Strategy. Available at: https://www.accenture.com/_acnmedia/accenture/conversionassets/dotcom/documents/global/pdf/strategy_8/accenture-manufacturing-ecosystems.pdf [Accessed by $06 / 19 / 2018]$

[37] Wei, Z., Song, X., \& Wang, D. (2017). Manufacturing flexibility, business modeldesign, and firm performance. International Journal of Production Economics, 193, 87-97.

[38] Hao, Y., Shamsuzzoha, A., \& Helo, P. (2013). Designing of virtual factory information system by enterprise portal. In 17th IEEE International Enterprise Distributed Object Computing Conference Workshops (EDOCW), pp. 258-266.

[39] Alfaro Saiz, J., Rodriguez, R., \& Ortiz, A. (2005). A performance mea surement system for virtualand extended enterprises. In Collaborative networks and their breeding environments. Boston: Springer.

[40] Ai, Q. S., Mo, K., Wang, Y., \& Zhao,L. (2013). Research of product information sharing system ba sed on cloud manufacturing. In Applied Mechanics and Materials (Vol. 248,pp. 533-538). Trans Tech Publications.

[41] Rong, K., Shi, Y., \& Yu, J. (2013). Nurturing business ecosystems to deal with industry uncerta inties. Industrial Management \& Data Systems, 113(3), 385-402.

[42] Guna sekaran, A., \& Ngai, E. W. (2004). Virtual supply-chain management. Production Planning \& Control, $15(6), 584-595$.

[43] Fujii, S., Kaihara, T., \& Morita, H. (2000). A distributed virtual factory in agile manufacturing environment. International Journal of Production Research, 38(17), 4113-4128.

[44] Shamsuzzoha,A., Ferreira, F., Azevedo, A., \& Helo, P. (2016). Collaborative smart process mo nitoring within virtual factory environment: An implementation issue. International Journal of Computer Integrated Manufacturing, 1-15.

[45] Lu, Y., Liu, C., Kevin, I., Wang, K., Huang, H., \& Xu, X. (2020). Digital Twin-driven smart manufacturing: Connotation, reference model, applications and research issues. Robotics and Computer-Integrated Manufacturing, 61, 101837. 
[46] Zhao, C., Luo, X., \& Zhang, L. (2020). Modeling of service agents for simulation in cloud manufacturing. Robotics and Computer-Integrated Manufacturing, 64, 101910.

[47] Basole, R. C., Russell, M. G., Huhtamäki, J., Rubens, N., Still, K., \& Park, H. (2015). Understanding business ecosystem dynamics: A data -driven approach. ACM Transactions on Management Information Systems (TMIS), $6(2), 6$.

[48] Reynolds, E. B., \& Uygun, Y. (2017). Strengthening advanced manufacturing innovation ecosystems: The case of Massachusetts. Technological Forecasting and Social Change.https://doi.org/10.1016/j.techfore.2017.06.003

[49] Hao, Y. (2016). Cloud Manufacturing: Strategic Alignment between Manufacturing Industry and Cloud Computing. Doctoral dissertation, University of Vaasa, Vaasa.

[50] Rong, K., Hu, G., Lin, Y., Shi, Y., \& Guo, L. (2015). Understanding business ecosystem using a 6C framework in Internet-of-Things-based sectors. International Journal of Production Economics, 159, 41-55.

[51] Sniderman, B., Mahto, M. \& Cotteleer, M.J. (2016). Industry 4.0 and manufacturing ecosystems. Exploring the world of connected enterprises. Deloitte University Press.

[52] Freitag, M., Westphal, I., \& Guglielmina, C. (2012). Service innovation life cycle in a manufacturing ecosystem. In Proceedings of New Generation Enterprise and Business Innovation Systems, Gdansk (Poland), pp. 71 -78

[53] Iansiti, M., and R. Levien. 2004. The Keystone Advantage: What the New Dynamics of Business Ecosystems Mean for Strategy, Innovation, and Sustainability. Boston, MA: Harvard Business School Press.

[54] Mubarok, K., Xu, X., Ye, X., Zhong, R. Y., \& Lu, Y. (2018). Manufacturing service reliability a ssessment in cloud manufacturing. Procedia CIRP, 72, 940-946.

[55] Fosch-Villaronga, E., \& Millard, C. (2019). Cloud robotics law and regulation: Challenges in the governance of complex and dynamic cyber-physical ecosystems. Robotics and Autonomous Systems, 119, 77-91.

[56] Xu, X (2012). From cloud computing to cloud manufacturing. Robotics and Computer-IntegratedManufacturing. 28(1), 75-86.

[57] Huang, B., Li, C., Yin, C., \& Zhao, X. (2013). Cloud manufacturing service platform for small-and mediumsized enterprises. The International Journal of Advanced Manufacturing Technology, 65(9-12), 1261-1272.

[58] Wang, X. V., Wang, L., Mohammed, A., \& Givehchi, M. (2017). Ubiquitous manufacturing system based on Cloud: A robotics application. Robotics and Computer-Integrated Manufacturing, 45, 116-125. 
[59] Verdouw, C. N., Beulens, A. J., Reijers, H. A., \& van der Vorst, J. G. (2015). A control model for object virtualization in supply chain management. Computers in Industry, 68, 116-131.

[60] Wang, X. V., \& Xu, X. W. (2013). An interoperable solution for Cloud manufacturing. Robotics and ComputerIntegrated Manufacturing, 2013;29(4):232-247.

[61] Gould, L.S. (2014). Plex's cloud ERP goes beyond finite. Automotive Design \& Production; Sep 2014, 126 (9), pp.40.

[62] Wu, D., Rosen, D. W., Wang, L., \& Schaefer, D. (2015). Cloud-based design and manufacturing: A new pa radigm in digital manufacturing and design innovation. Computer-Aided Design, 59, 1-14.

[63] Luo, Y. L., Zhang, L., He, D. J., Tao, F., Ren, L. \& Tao, F. (2011). Study on multi-view model for cloud manufacturing. Advanced Materials Research, 201, 685-688.

[64] Helo, P., \& Hao, Y. (2017). Cloud manufacturing system for sheet metal processing. Production Planning \& Control, 28(6-8), 524-537.

[65] Helo, P., Suorsa, M., Hao, Y., \& Anussornnitisarn, P. (2014). Toward a cloud-based manufacturing execution system for distributed manufacturing. Computers in Industry, 65(4), 646-656.

[66] Shamsuzzoha,A., Toscano, C., Carneiro, L. M., Kumar, V., \& Helo, P. (2015). ICT-based solution approa ch for collaborative delivery of customised products. Production Planning \& Control, 1-19.

[67] Suh, N. P. (2010) Axiomatic Design: Advances and Applications, Oxford University Press, Indian Edition.

[68] Kurfess, T., \& Cass, W. J. (2014). Rethinking additive manufacturing and intellectual property protection. Research-Technology Management, 57(5), 35-42.

[69] Kim, S. J., Suh, N. P., \& Kim, S. G. (1991). Design of software system ba sed on axiomatic design. CIRP annals, $40(1), 165-170$.

[70] Letaifa, S.B., Gratacap, A., Isckia, T. (2013) Understanding business ecosystems: how firms succeed in the new world of convergence?De Boeck Superieur, Méthodes \& Recherches, ISSN 1781-4944. 